PNL-3361

UC-11

\title{
Operating Manual for Ford's Farm Range Air Samplers
}

\author{
J. A. Glissmeyer
}

M. A. Halverson

October 1980

Prepared for the U.S. Army

under a Related Services Agreement

with the U.S. Department of Energy

Contract DE-AC06-76RLO 1830 


\title{
NOTICE
}

This report was prepared as an account of work sponsored by the United States Government. Neither the United States nor the Department of Energy, nor any of their employees, nor any of their contractors, subcontractors, or their employees, makes any warranty, express or implied, or assumes any legal liability or responsibility for the accuracy, completeness or usefulness of any information, apparatus, product or process disclosed, or represents that its use would not infringe privately owned rights.

The views, opinions and conclusions contained in this report are those of the contractor and do not necessarily represent those of the United States Government or the United States Department of Energy.

\author{
PACIFIC NORTHWEST LABORATORY \\ operated by \\ BATTELLE \\ for the \\ UNITED STATES DEPARTMENT OF ENERGY \\ Under Contract EY-76-C-06-1830
}
Printed in the United States of America
Available from
National Technical Information Service
United States Department of Commerce
5285 Port Royal Road
Springfield, Virginia 22151

Price: Printed Copy $\mathbf{\$}$

$\therefore$ Microfiche $\$ 3.00$

NTIS

-Pages Selling Price

$\begin{array}{lr}001-025 & \$ 4.00 \\ 026-050 & \$ 4.50 \\ 051-075 & \$ 5.25 \\ 076-100 & \$ 6.00 \\ 101-125 & \$ 6.50 \\ 126-150 & \$ 7.25 \\ 151-175 & \$ 8.00 \\ 176-200 & \$ 9.00 \\ 201-225 & \$ 9.25 \\ 226-250 & \$ 9.50 \\ 251-275 & \$ 10.75 \\ 276-300 & \$ 11.00\end{array}$


OPERATING MANUAL FOR FORD'S

FARM RANGE AIR SAMPLERS

J. A. Glissmeyer

M. A. Halverson

October 1980

Prepared for

the U.S. Army

under a Related Services Agreement

with the U.S. Department of Energy

Contract DE-ACO6-76RLO 1830

Pac if ic Northwest Laboratory

Richland, Washington 99352 


\section{ABSTRACT}

An air-sampling program was designed for a target enclosure at the Ford's Farm Range, Aberdeen Proving Ground, Maryland, where the Army test-fires tungsten and depleted-uranium armor penetrators. The primary potential particle inhalation hazard is depleted uranium. The sampling program includes workplace and filtered exhaust air sampling. Conventional isokinetic stack sampling was employed for the filtered exhaust air. Because of the need for rapid monitor response to concentration increases and decreases, conventional radioactive particle monitors were not used. Instead, real-time aerosol monitors employing a light-scattering technique were used for monitors requiring a fast response. For other monitoring functions, piezoelectric and beta-attenuation respirableparticle sampling techniques were used. The application of these technologies to the monitoring of airborne radioactive contaminants is addressed. Sampler installation and operation are detailed. 


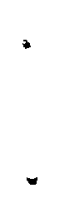

.
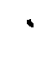
ABSTRACT

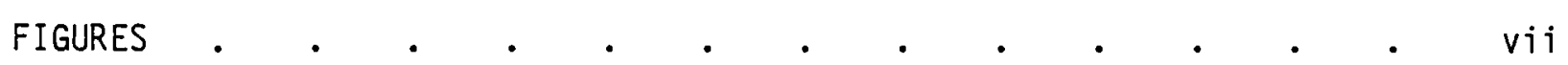

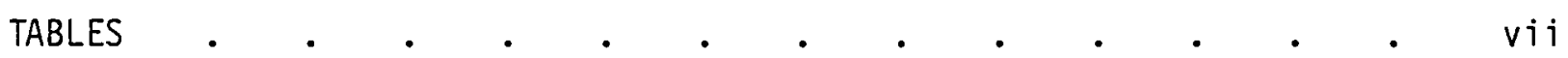

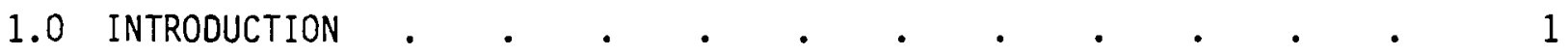

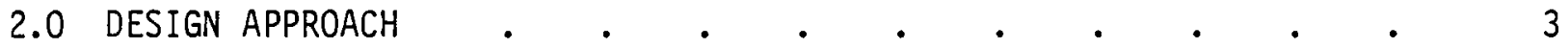

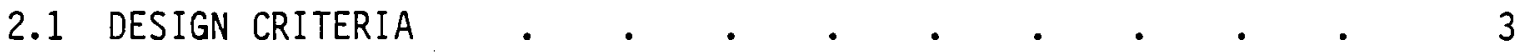

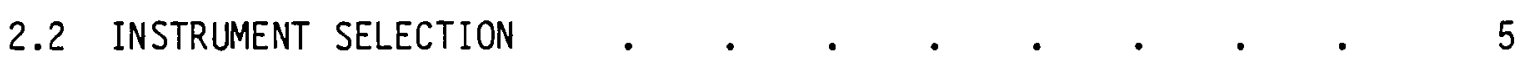

2.2.1 Exhaust and Inlet Monitors . . . . . . . 6

2.2.2 Workplace Monitor • . . . . . . . . $\quad 7$

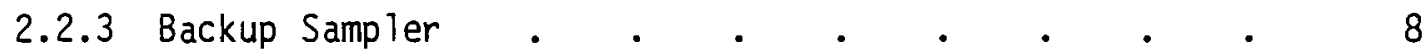

2.3 ACTION LEVELS .

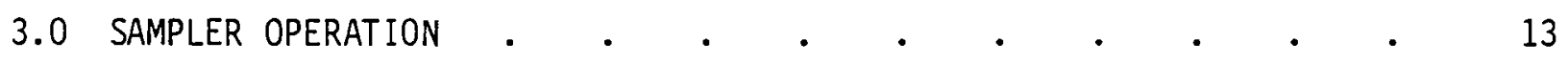

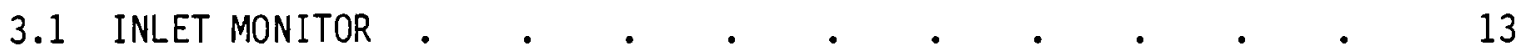

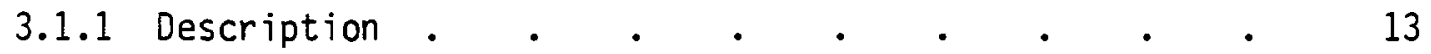

3.1 .2 Operation . $\quad . \quad$. $\quad . \quad$. . . . 17

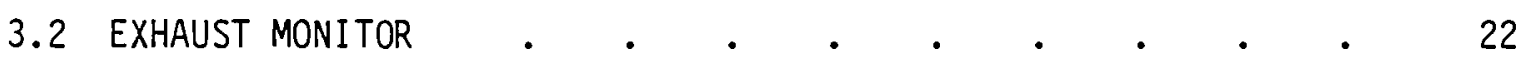

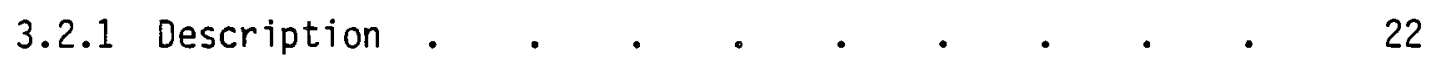

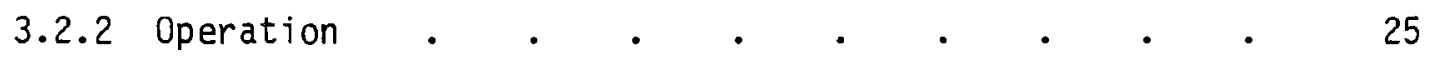

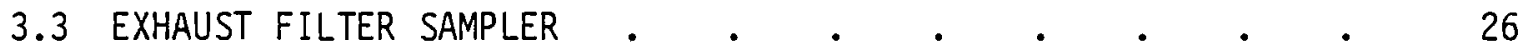

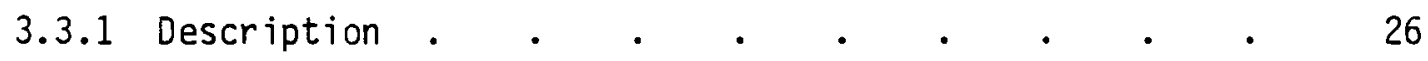

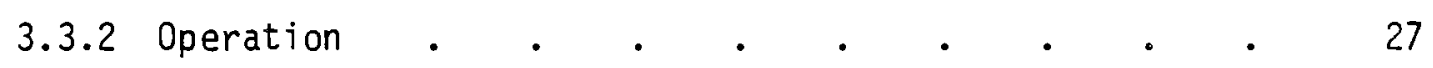

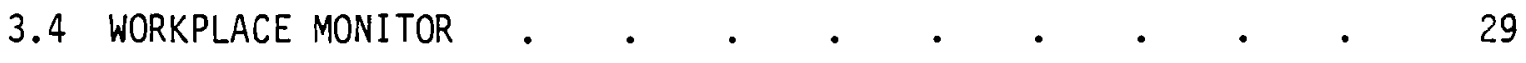

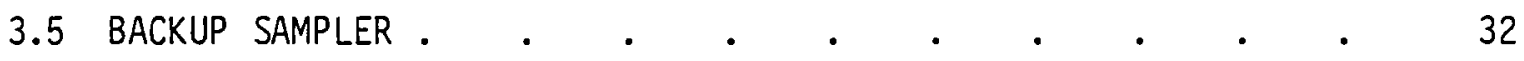




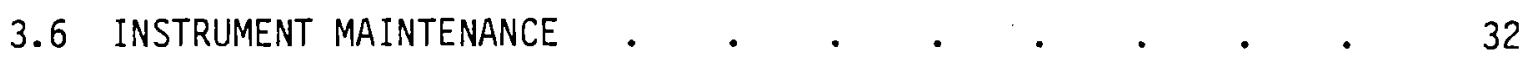

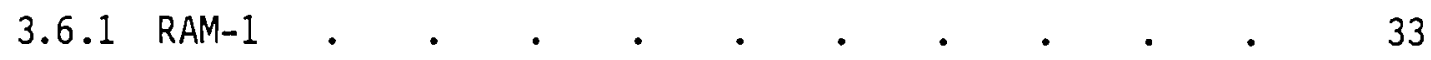

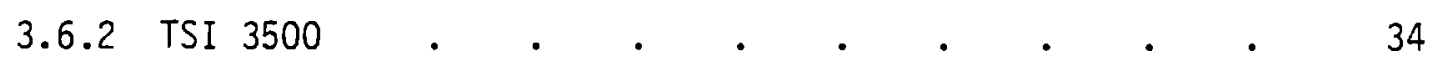

3.6.3 Yokogawa Model 3056-11 Recorder . . . . . 34

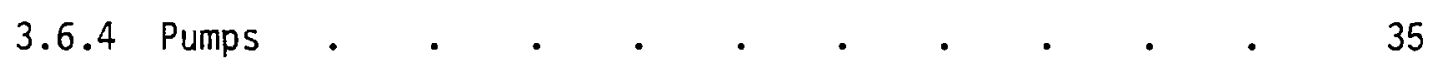

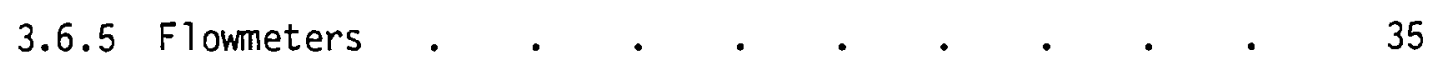

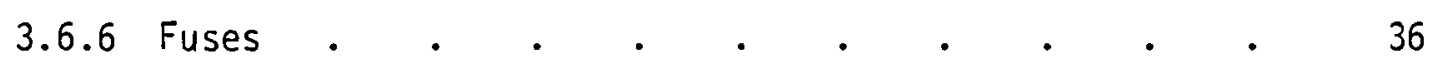

3.6 .7 Contamination $\quad . \quad$. . . . . . . . . 36

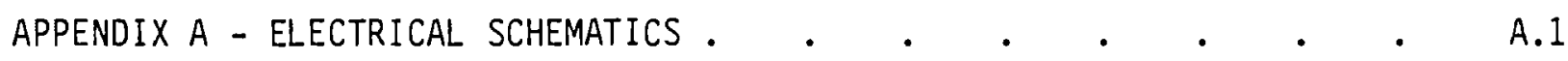

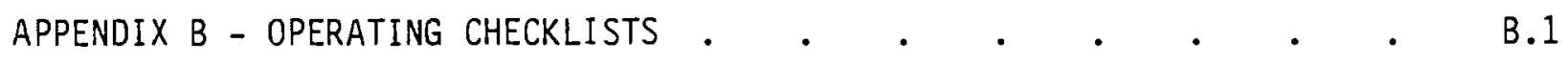




\section{FIGURES}

1 Top View of Target Enclosure and Location of Samplers . $\quad$ e 2

2 Penetration Characteristics of the Cyclone Preseparator

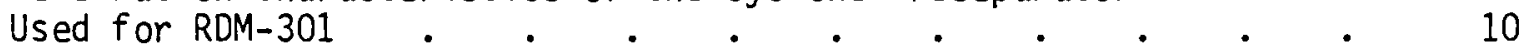

3 Inlet Monitor Vacuum and Purge Systems . . . . . . . 14

4 Inlet Monitor Electronic Component Block Diagram . $\quad$ • . $\quad$ - 15

5 Exhaust Monitor Vacuum System . . . . . . . . . . $\quad 23$

6 Exhaust Monitor Electronic Component Block Diagram . . . 24

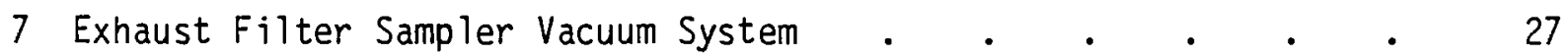

8 Exhaust Filter Sampler Instrumentation Block Diagram $\quad$ - . $\quad 28$

9 GCA Model RDM-301 Range Limits . . . . . . . . . 30

10 Installation of Filter and Desiccant Cartridges in RAM-1 . $\quad 33$

A.1 Inlet Monitor RAM-1 Signal Switch Box • . . . . . . A.1

A.2 Inlet Monitor Solenoid Valve Control Electrical Schematic . . A.1

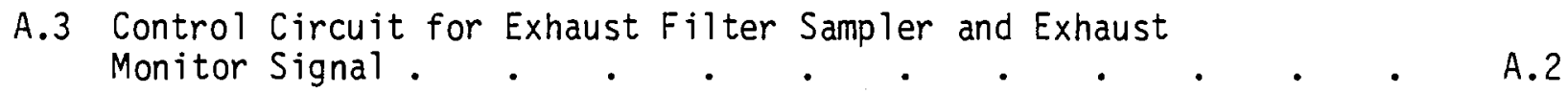

\section{$\underline{\text { TABLES }}$}

1 Inlet Monitor Flowmeter Set Points for Achieving $155 \mathrm{SCFH}$. $\quad 18$

2 Inlet Monitor Recorder and Digital Voltmeter Interpretation . . 21

3 Exhaust Monitor Flowmeter Set Points for Achieving $95 \mathrm{SCFH}$. $\quad 25$

4 Exhaust Filter Sampler Flowmeter Set Points for Achieving

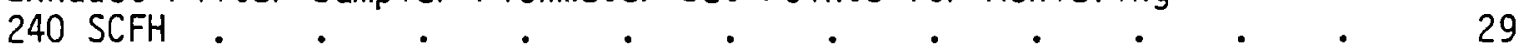

5 Suggested Maintenance Schedule for TSI 3500 Piezobalance • • 35

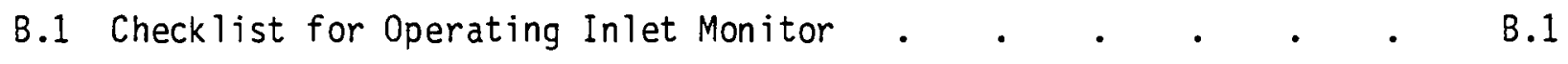

B.2 Checklist for Operating Exhaust Monitor . . . . . . . B.2

B.3 Check list for Operating Exhaust Filter Sampler . . . . . B.2 



\subsection{INTRODUCTION}

The air-sampling system is designed for the target enclosure at the Ford's Farm Firing Range, Aberdeen Proving Ground, Maryland. The Ford's Farm Range is used for test firing of tungsten and depleted-uranium kinetic-energy penetrators (projectiles). The 20-ft-wide, 40-ft-long, 20-ft-high enclosure (shown in Figure 1) houses the target stand and is ventilated at the rate of $510 \mathrm{~m}^{3} / \mathrm{min}$ $(18,000 \mathrm{cfm})$. The ventilation exhaust is filtered using high-efficiency pleated filters to minimize release of particulates to the environment. During the test firing, air enters the enclosure through the 2-1/2-ft-dia projectile entry port shown in the figure. While the targets are being set, the sliding door is open and air enters through the doorway.

The enclosure greatly reduces the release of test firing-generated particulates to the environment but at the same time tends to concentrate the inhalation and radiation hazard to the workers who enter the enclosure after the test firing. Therefore, a radiation monitoring program, including air sampling, is required. The objectives of the enclosure air-sampling system are to:

- collect a representative sample of the particulate effluent for subsequent radionuclide analysis;

- continuously monitor the particles present in the exhaust for loss of filter integrity;

- indicate when the particle concentration in the enclosure after a test firing has decreased to a level safe for personnel entry;

- indicate, while personnel are in the enclosure, when the concentration in the workplace exceeds a set action level; and

- record the particle concentration in exhaust and workplace.

The report is divided into two parts. In Section 2.0 , the design approach for the sampling program is discussed. Section 3.0 was written for the sampling system operator and details the installation and operation of the five 


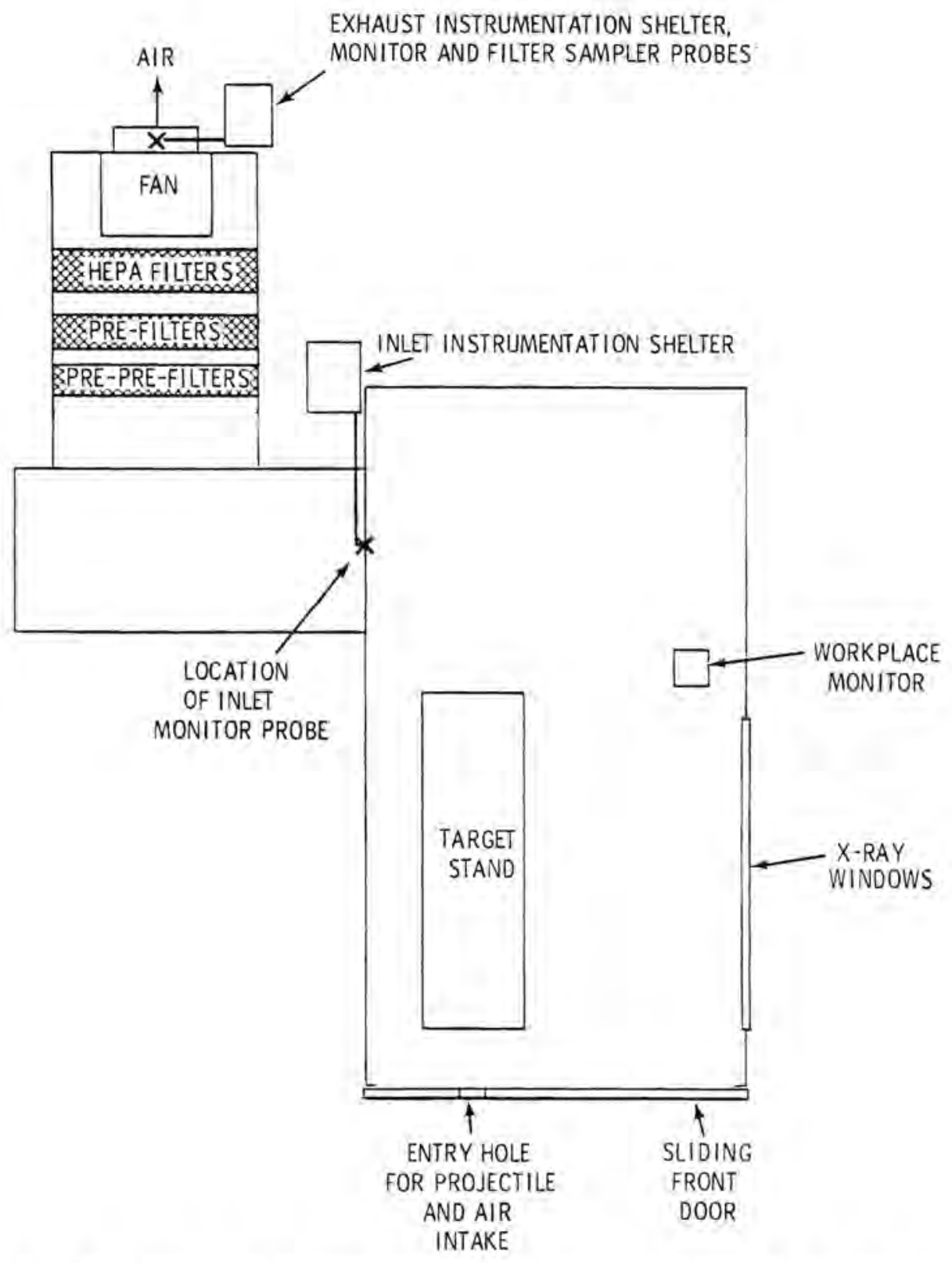

FIGURE 1. Top View of Target Enclosure and Location of Samplers (drawing not to scale; enclosure is approximately $20 \mathrm{ft}$ by $40 \mathrm{ft}$ )

sampling devices chosen to fulfill the objectives listed above. It is assumed that the system operator will have studied the manufacturer's instrument manuals before attempting to operate the integrated sampling system. 


\subsection{DESIGN APPROACH}

The general approach taken in designing the target enclosure air-sampling program is discussed in this section. The functions to be served by the airsampling program were listed in the introduction. The criteria for selecting instrumentation to meet those functions will be treated first. The operating principles of the samplers chosen for each sampling function will then be described. Finally, the determination and interpretation of action levels for al arm actuation are addressed.

\subsection{DESIGN CRITERIA}

Five sampling systems constitute the routine air-sampling program fulfilling the objectives given in Section 1.0. These five systems and their functions are:

- exhaust sampler for collecting representative samples of particles in the filtered exhaust air for subsequent radionuclide analysis;

- exhaust monitor for detecting a loss of effective air filtration,

- inlet monitor at the inlet of the ventilation duct in the enclosure for indicating the decline of particle air concentration in the enclosure after a test firing or a concentration increase when the enclosure is occupied,

- workplace monitor to indicate when the airborne uranium concentration in the enclosure, when it is occupied, exceeds a set level; and a

- back-up sampler used to quickly measure air concentration in any location when other systems fail, or to verify that the enclosure is safe for personnel entry.

The action level, or the concentration of concern, for the exhaust sampler and monitor is that given in the Code of Federal Regulations(a) for

(a) Code of Federal Regulations, Title 10, Part 20, Appendix B, 1980. Abbreviated 10 CFR 20. 
nonoccupational exposure to uranium-238, $3 \times 10^{-12} \mu \mathrm{Ci} / \mathrm{ml}$. The exhaust sampler is to collect particles while the exhauster is operated, which is about $6 \mathrm{~h} / \mathrm{d}$, $5 \mathrm{~d} / \mathrm{wk}$. Enough sample is to be collected during a week's operation to permit accurate analys is and determination of the concentration given above. On the other hand, the exhaust monitor is to indicate when the above concentration is exceeded for 15 min. A dynamic range of 3 orders of magnitude is felt adequate for the exhaust monitor.

The inlet monitor is to detect, within $5 \mathrm{~min}$, when the airborne uranium concentration in the enclosure after the test firing falls below $7 \times 10^{-11}$ $\mu \mathrm{Ci} / \mathrm{ml}$, the maximum permissible concentration (MPC) for occupational exposure to uranium-238 given in 10 CFR 20. The monitor is also expected to indicate within 5 min when the concentration exceeds the MPC again. A dynamic range of 5 orders of magnitude is desired. The monitor is to be operated unattended for at least an hour. Data readout is to be remote. The monitor must be able to withstand the shock wave and very high particle concentration generated in the enclosure when the ammunition impacts the target. A concentration reading bias within a factor of two is judged to be sufficient.

The workplace monitor is to be put into place when personnel enter the enclosure after the test firing. It requires a dynamic range of 3 orders of magnitude. An alarm is to be sounded when the occupational MPC is exceeded for $5 \mathrm{~min}$. A fast response is required because personnel on ly occupy the enclosure for 15 to $30 \mathrm{~min}$ between test firings. Concentration measurements are to be recorded and the vacuum supply is to be built in.

The back-up sampler is to be able to make a measurement of MPC with a 5-min sample. Separate sample analysis is to be avoided and the instrument is to be portable so measurements could be made any place in the enclosure.

An overall limiting factor in the system design was that the system installation was to be completed within $3 \mathrm{mo}$. The instrumentation selected to meet these criteria is described in Section 2.2. Since the installation of the sampling systems, the action level for alarms on a 17 the systems has been changed to $25 \%$ of the occupational MPC as a safety precaution. The effect of this on instrument use and performance will be addressed in Section 2.3. 


\subsection{INSTRUMENT SELECTION}

The selection of a technique for collecting a sample of the exhausted airborne particles was straightforward. Sample collection is accomplished using two in-stack filter holders with intake nozzles sized for isokinetic sampling. Because there is no stack or a suitable length of straight duct, this sampler is situated at the fan discharge. This facilitates the changing of samples because the filter holders can be easily reached through the gravity damper on the fan housing. The sampler intakes are located at points of average velocity for the duct cross section to attempt to collect particle samples representative of the airflow.

The selection of the instruments for the other samplers was more difficult. Initially, conventional radioactive particle monitors (commoniy called continuous air monitors, CAM's) sensitive to alpha radiation were considered. This approach, however, was rejected on two counts.

First, the typical CAM collects airborne particles on a filter and monitors their cumulative quantity. Alarm annunicators are provided when the accumulated radioactive particles exceed a set quantity. The fact that a CAM monitors an accumulation makes it unsuitable without modification for indicating when the concentration has decreased to a given level as required for the inlet monitor. This reasoning held also for the workplace monitors because it was just as important to quickly know when the air concentration returned to a safe level as to know when it was too high.

Second, it was felt that the typical CAM had insufficient sensitivity for the rapid response required by the criteria. At an occupational MPC average concentration the air would contain 155 disintegrations per minute (dpm) of uranium per cubic meter which, with a typical 10\% counting efficiency, would only yield a monitor response of 16 counts per minute (cpm) per cubic meter of

sampled air. With a typical flow rate of $0.05 \mathrm{~m}^{3} / \mathrm{min}$, the accumulated quantity is $4.0 \mathrm{cpm}$ after $5 \mathrm{~min}$ which is not much more than sensor background. With the action level now set at $25 \%$ MPC, the sensitivity problem is even more severe. 
To acquire a CAM to meet the design criteria would have required that custom units with micropressing be built. Therefore, it was decided to look for different measurement methods available on short notice. If subsequent experience shows that the criteria need not be so restrictive on response time, CAM's should be reconsidered for future firing ranges to take advantage of their selectivity for radioactive particles.

To achieve rapid particle concentration measurement, the selectivity for radioactive particles was sacrificed. The sampling methods considered were light scattering, beta-attenuation, and piezoelectricity. The following subsections will explain the instrumentation selected to perform the monitoring functions and give brief descriptions of their operating principles.

\subsubsection{Exhaust and Inlet Monitors}

Two Real-Time Aerosol Monitors, Model RAM-1, (a) which employ a lightscattering technique, were selected for monitoring particle concentrations at the ventilation exhaust and intake positions. While the response of this instrument is partly dependent on particle characteristics, its nearly instantaneous response made it ideal for its qualitative role. The exhaust monitor samples particles of all sizes while the inlet monitor samples only respirable particles which approximate those retained in the lower respiratory tract. This inlet monitor is exposed to extremely high concentrations $\left(>100 \mathrm{mg} / \mathrm{m}^{3}\right)$; therefore, to reduce interior contamination of the sampler, a probe purge and a cyclone at the probe intake were installed to limit the number of large particles sampled.

Data from the exhaust monitor is not normally compared to that of the inlet monitor. The exhaust monitor samples all particle sizes in the exhaust air instead of having a cyclone to separate out the nonrespirable particles. However, it is expected that when the ventilation system operates normally, particles in the filtered exhaust air would be in the respirable range. If large nonrespirable particles are present, the monitoring system would then

(a) Manufactured by GCA Corporation, Bedford, Massachusetts. 
tend to overestimate the respirable hazard. Experience will show to what degree the readings from both monitors can be compared, for instance, for calculating filtration efficiency.

Light-scattering instruments work on the principle that when light strikes an airborne particle, light is scattered in all directions. The intensity of the scattered light is a function of direction, particle size, shape, and refractive index. Light-scattering instruments such as the RAM-1 that collect light in a forward direction (with respect to the incident beam) are less sensitive to irregularities in particle shape than other light-scattering instruments. Because of the complexities involved, light-scattering instruments yield an inferred reading of mass concentration based on a calibration with a test aerosol.

In the RAM-1 the light source is a pulsed Ga-As light-emitting diode, and the near-forward direction scattered light is sensed by a photodetector. Many particles are in the illuminated volume at a time. The RAM-1s are calibrated using a standard Arizona road-dust aerosol. If the instrument response to depleted uranium dioxide is different than for the standard aerosol, a correlation between the road-dust aerosol equivalent concentrations (as on the instrument) and the actual concentration of uranium oxide or tungsten oxide can be obtained by taking filter samples during the first series of test firings; or by using a calibration apparatus. The correlation may yield a correction that can be applied to the calibration of the instrument to allow direct readings of the aerosol concentration in the enclosure.

\subsubsection{Workplace Monitor}

Workplace monitoring is partly carried out in a qualitative fashion by the light-scattering sampler at the exhaust intake. Additionally, it is desirable to have some monitoring instrumentation that is not as sensitive to particle characteristics but would respond to particle mass. Therefore, an instrument using the beta-attenuation technique was selected for a semi-fixed monitor. The beta-attenuation instrument chosen for this air-sampling function is the GCA Corporation Model RDM-301 Recording Respirable Dust Monitor. 
Beta-attenuation instruments work on the principle that a beam of electrons (beta particles) is partially absorbed (attenuated) by a mass of particles. The amount of attenuation is almost directly proportional to the amount of mass per unit area for a given radioactive source, and the attenuation is essentially independent of the chemical composition of the aerosol. The RDM-301 samples air and collects the entrained particles on a mylar film. To obtain a reading of collected mass, a background count is taken on the blank mylar film, followed by the period of particle sampling. A final count gives the surface concentration of particles. Knowing the air-sampling rate and the sampling time allows the airborne concentration to be calculated. The RDM-301 performs all these functions automatically and repeatedly, and records the results on a paper tape. The RDM-301 can be used to monitor total particle concentration or respirable particle concentration using a small cyclone on the intake. It is normally used for monitoring respirable particles.

\subsubsection{Backup Sampler}

For a backup sampler it was desirable to have an instrument that was portable and that directly responded to the mass of particles sampled. Therefore, a Thermosyștems Incoporated(a) (TSI) Model 3500 Piezobalance using a piezoelectric mass sensing technique was selected. Piezoelectric instruments work on the principle that the vibrational frequency of a quartz crystal in an oscillator circuit changes when mass accumulates on the crystal. This vibrational frequency change is directly proportional to the accumulated mass over a certain range. By depositing the airborne particles on a crystal with an electrostatic precipitator and knowing the sample flow rate, a direct measurement of the mass concentration of the airborne particles can be made. The measurement process is sensitive to changes in humidity while the mass is being deposited since a change in humidity leads to a change in absorbed water on the particles, which in turn leads to a change in the particles' mass. The technique is also sensitive to particle size to the extent that accurate response is limited to particles smaller than $10 \mu \mathrm{m}$ because larger particles

(a) Thermosystems Incorporated, P.0. Box 43394, St. Paul, Minnesota 55164. 
do not perfectiy adhere to the crystal surface. The method is, therefore, best suited for monitoring respirable particles; therefore, a preseparator is used on the instrument intake to remove them.

The TSI-3500 allows measurements of concentration as $10 \mathrm{w}$ as $0.01 \mathrm{mg} / \mathrm{m}^{3}$ with a 2-min sampling time. It weighs only $9.51 \mathrm{~b}$ and is carried on a shoulder strap. This portability enables the instrument to be used by a technician to determine if there is an inhalation hazard in any location around the enclosure or firing range. The instrument can be used as a rough cross-check on the other samplers.

\subsection{ACTION LEVELS}

Before operating the sampling systems, it is important to decide on action levels for each instrument. The method of concentration measurement, the origins of the published MPC and the instruments' background concentration measurements need to be considered in order to select an action level.

As described in Section 2.2, three of the monitoring instruments operate with a respirable preseparator on the intake to the instrument. These are the TSI 3500 backup sampler, the RDM-301 workplace sampler and the RAM-1 Inlet Monitor. The preseparator is either a cyclone or an impactor. The function of the preseparator is to allow mainly respirable particles to pass into the monitor. Each preseparator has a cutpoint of 3.5-um aerodynamic equivalent diameter (AED). (a) This means that half of the 3.5-um particles penetrate the preseparator and half do not. A decreasing percentage of particles $>3.5 \mu \mathrm{m}$ and an increasing percentage of particles $<3.5 \mu \mathrm{m}$ penetrate the device as shown in Figure 2. This roughly simulates the retention of particles in the upper respiratory tract, permitting so-called "respirable particles" (those that would deposit in the lower respiratory tract) to be monitored.

(a) The diameter of a sphere of water that behaves aerodynamically the same as the real particles being sampled. The AED is an important parameter affecting a particle's behavior and its probability of being retained in the respiratory system. For spherical particles, AED $=$ diameter $x$ $\sqrt{\text { specific gravity. }}$ 


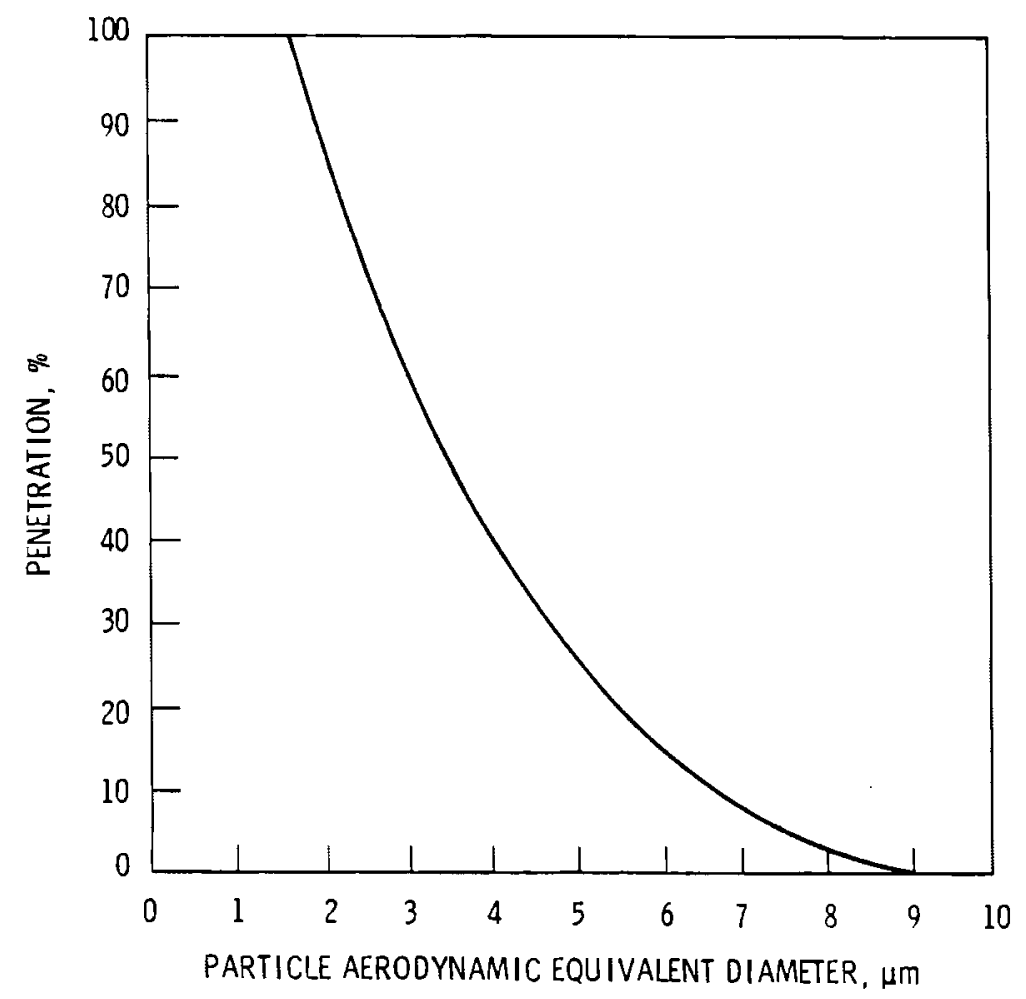

FIGURE 2. Penetration Characteristics of the Cyclone Preseparator Used for RDM-301 (per GCA Instruction Manual)

The simulation is, of course, not exact for a number of reasons that we will not investigate here. (a)

Respirable preseparators are not in wide use in the monitoring of airborne radioactive particles because of difficulties in using them and their inexact simulation of the upper respiratory tract. MPC's are not published for sampling only respirable particles. The MPC for ${ }^{238} \mathrm{U}$ given in 10 CFR 20 is based upon values published by the International Commission on Radiological Protection (ICRP). (b) The ICRP based the MPC on experimental data related to the fate of uranium in the body, $(\mathrm{C})$ and on the following assumptions: 1) $25 \%$ of

(a) For a good discussion of respirable activity samplers, see Thomas $T$. Mercer, Aerosol Technology in Hazard Evaluation, Academic Press, New York, NY, 1973, pp. 284-318.

(b) Report of Committee II on Permissible Dose for Internal Radiation, 1959, International Commission on Radiological Protection, Publication 2, Pergamon Press, New York, NY, Table 10.

(c) Summarized by S. R. Bernard, "Maximum Permissible Amounts of Natural Uranium in the Body, Air and Drinking Water Based on Human Experimental Data," Health Physics, Vol. 1, pp. 288-305, 1958. 
airborne uranium is deposited in the lower respiratory (a) tract, 2) the deposited uranium in soluble, and 3 ) the concentration is averaged for a 40-h/wk exposure of a standard man. The published MPC is then interpreted to be applicable to measurements of total airborne uranium regardless of particle size. The purpose of this approach was to allow an approximate determination of when a critical inhalation dose is exceeded by simply sampling all sizes of airborne particles and analyzing for uranium.

For instruments monitoring what are considered respirable particles, it is appropriate to base action levels on a respirable MPC. If the respirable fraction of airborne uranium is $25 \%$, then the respirable MPC for soluble uranium is $2 \times 10^{-11} \mu \mathrm{Ci} / \mathrm{ml}$ or $0.05 \mathrm{mg} / \mathrm{m}^{3}$.

An action level is a tool used to avoid personnel exposure to average airborne uranium concentrations on the order of MPC. Therefore, alarm set points on monitoring instruments are oten set to warn of average concentrations exceeding some fraction of MPC, for instance, $1 / 4 \mathrm{MPC}(1 / 4 \times 0.05=$ $\left.0.012 \mathrm{mg} / \mathrm{m}^{3}\right)$. A preliminary analysis of data taken with the sampling systems prior to any test firing showed an average ambient dust concentration of about $0.015 \mathrm{mg} / \mathrm{m}^{3}$ (a mass dust concentration, not a uranium concentration). This value is then already higher than the 1/4 MPC action level, which points out a need for careful examination of background data from each instrument to establish average ambient concentration and expected fluctuation. Then, an action level can be set between the MPC and either the average background or highest fluctuation of background. The RDM-301 takes a reading averaged over many minutes, and the RAM-1 and the TSI-3500 take readings averaged over many seconds. The degree of ambient dust concentration fluctuation is then expected to vary between instruments. This may result in different action levels for each instrument.

Until a detailed analysis of background sampling data is done, it is suggested that the respirable MPC value of $0.05 \mathrm{mg} / \mathrm{m}^{3}$ be used as an action level

(a) "Deposition and Retention Models for Internal Dosimetry of the Human Respiratory Tract," Task Group on Lung Dynamics Report to Committee II of ICRP, Health Physics, Vol. 12, pp. 173-207. 
for all the samplers. This is justified because for the instrumentation used here a reading of concentration exceeding MPC gives a conservative warning of inhalation hazard for several reasons. First, the instruments respond to all particles regardless if they contain uranium. Second, a previous investigation has shown that not all the respirable uranium particles are soluble. (a) Third, the Exhaust Monitor monitors, without a respirable preseparator, all sizes of particles. As in any situation where exposure to hazardous dust is a possibility no matter how dilute, reducing the duration of the exposure is always advisable.

(a) J. A. Glissmeyer and J. Mishima, Characterization of Airborne Uranium From Test Firings of XM 774 Ammunition, PNL-2944, Battelle, Pac if ic Northwest Laboratory, Richland, Washington 99352, November 1979. 


\subsection{SAMPLER OPERATION}

This section describes the sampling systems in detail and how they are operated. It is expected that the operator is familiar with the manuals provided by the instrument manufacturers before attempting to operate the integrated system.

\subsection{INLET MONITOR}

\subsubsection{Description}

This portion of the air-sampling system samples the air as it enters the ventilation duct. Sampling the air at this point gives an indication of the overall quality of air in the enclosure. The primary function of the inlet monitor is to signal when the concentration of particles in the enclosure exceeds a set concentration. The monitoring system is designed to operate continuously during a working day. A diagram of the vacuum system is shown in Figure 3, and a block diagram of the major electronics is shown in Figure 4.

The monitoring system consists of a sample manifold, the monitoring instruments and a purge air supply. The sampling manifold begins at the $100-x$ 56-in. inlet of the enclosure ventilation duct just upstream of the baffles. A sample of the ventilation air is withdrawn through a Bendix Model 240 cyclone $^{(a)}$ at a flow rate of 159 standard $^{(b)}$ cubic feet per hour (SCFH) or 75 standard liter per minute (slpm). At this flow the cyclone has a particle-size cutoff of $3.5 \mu \mathrm{m}$ AED; therefore, on ly particles considered respirable are monitored by the system. $(c)$ The sampled air then passes through the manifold from which a subsample is taken (via an isokinetic nozzle) as the monitor input. The balance of the sampled exhaust is filtered, passed through a variable area

(a) Available through National Environmental Instruments, P.0. Box 590, Warwick, Rhode Is land 02888.

(b) At 700F, 1 atmosphere.

(c) The cyclone retains airborne particles much as the upper respiratory system does. Thus, the particles penetrating the cyclone are considered "respirable." See Morton Lippmann and Tai Chan, "Calibration of Dual Inlet Cyclones for Respirable Mass Sampling," American Industrial Hygiene Association Journal, April 1974. 


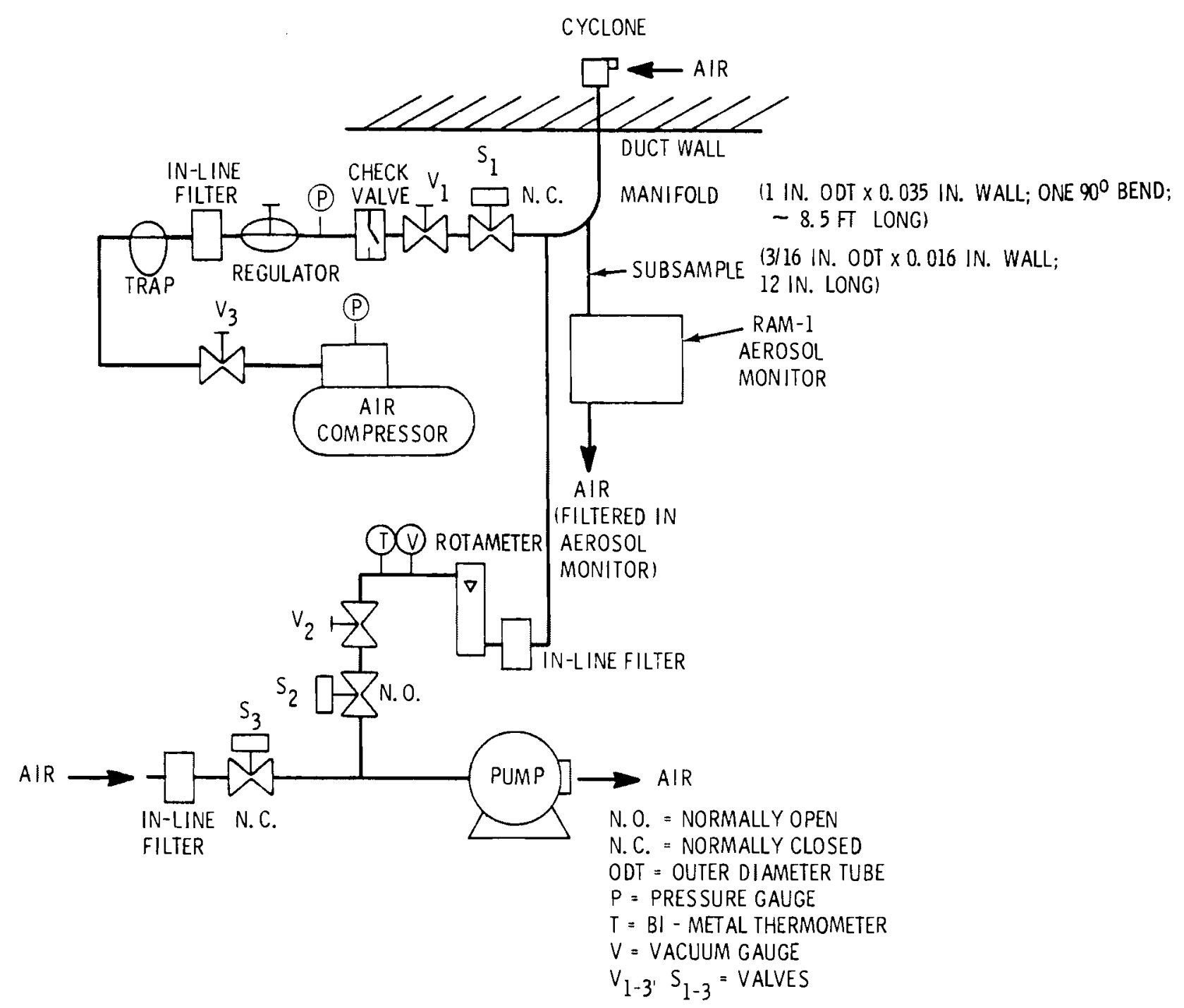

FIGURE 3. Inlet Monitor Vacuum and Purge Systems

flowmeter (rotameter) and regulating valve, and is expelled to the atmosphere through the vacuum pump: The temperature and vacuum gages aid the interpretation of flowmeter readings. The flowmeter measures the total sample airflow minus the subsample flow, and, therefore, will be set on a reading equivalent to $75-2=73$ lpm.

Part of the sample manifold is heat-traced to prevent moisture condensation inside the system and to raise the sample air temperature to the operating temperature of the monitoring instruments. The heat output is controlled by a variable transformer. Experience will determine the best heat setting 


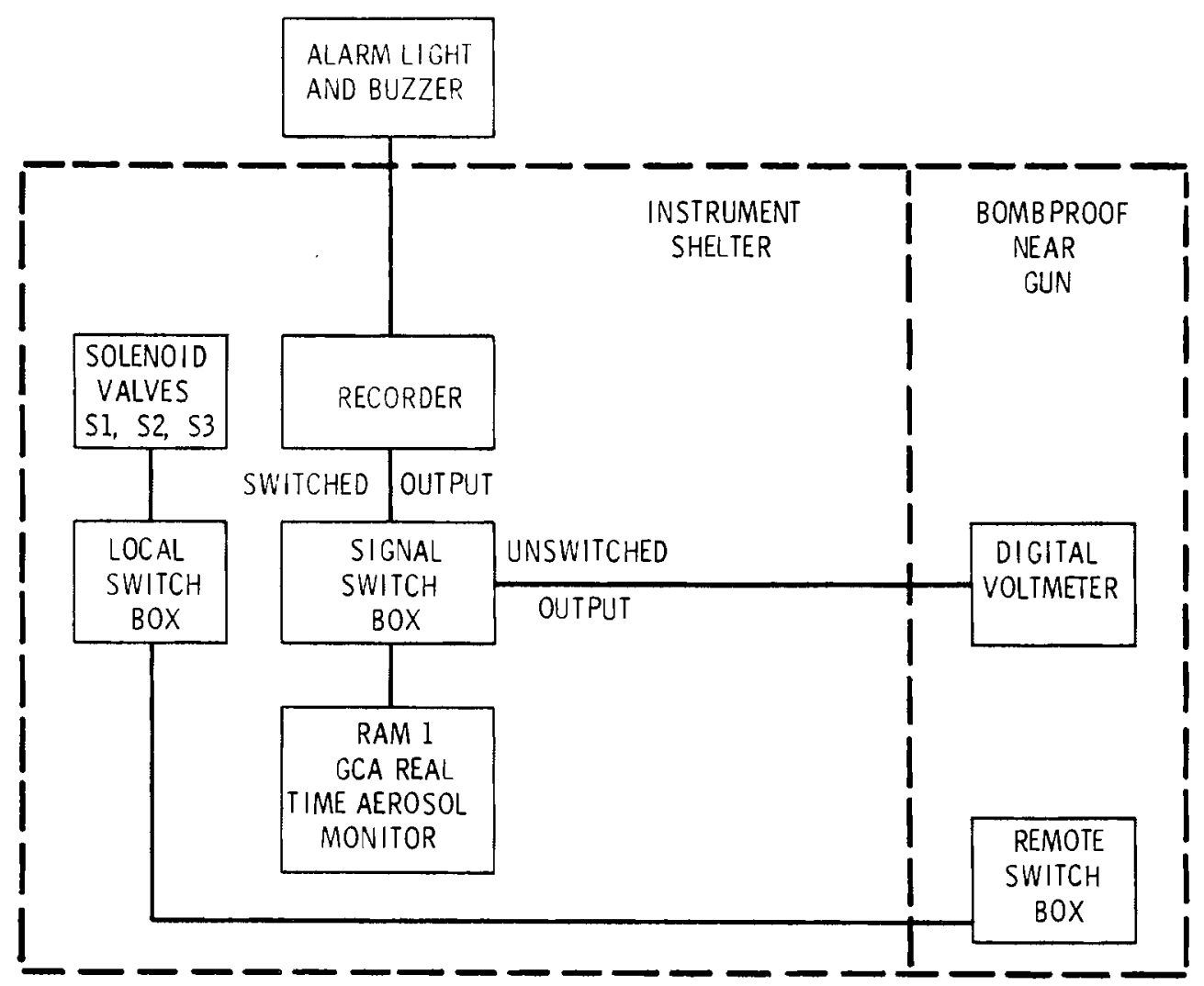

FIGURE 4. Inlet Monitor Electronic Component Block Diagram

to maintain sample air temperature. Temperature is indicated by the bi-metal thermometer downstream of the flowmeter.

The subsample stream is withdrawn from the manifold at a rate of $2 \mathrm{epm}$ and is passed through the GCA RAM-1. The RAM-1 senses the mass concentration (mg/ $\mathrm{m}^{3}$ ) of the particles in the sampled air. Because of the cyclone at the manifold inlet, the concentration of respirable particles in the ventilation air is indicated. The RAM-1 readout displays the concentration and supplies an external equivalent voltage signal. The voltage signal is then read remotely at the gun station by a portable digital voltmeter, and the particle concentration is interpreted from the voltage reading. This function enables a remote determination of when the particle concentration in the ventilation air is below safe limits. The RAM-1 output signal is also fed to a recorder with selectable high-level contacts to trip both audible and visual alarms if the concentration in ventilation air exceeds a preselected level. Provision 
is made to switch the signal to the recorder on or off as desired. A schematic of the switch box is included in Appendix A (Figure A.1).

The purge air supply backflushes the sample manifold during penetrator impact and the following moments of very high particle concentration. This is done for several reasons. First, unfiltered exhaust air concentration immediately following impact is of no concern to worker protection since no personnel are in the enclosure at this time. Second, the purge air reduces unnecessary sample manifold internal contamination that could conceivably be resuspended at any time giving rise to false monitor readings. Third, the purge air should reduce the need for system decontamination before hands-on maintenance. Finally, the purge air will help protect the RAM-1 optics and pump from the impact pressure pulse and the following extreme particle concentration.

The purge air supply consists of an air compressor, oil trap filter, regulator, check valve and regulating valve. The purging action is controlled by three solenoid valves, S1, S2 and S3, that are actuated simultaneously by either a local switch or a remote switch at the gun station (see Figures 3 and 4 and Figure A.2 in Appendix A). Valves S1 and S3 are normally closed, and valve $S 2$ is normally open allowing the pump to exhaust the sample manifold. Just before firing the round and for roughly 1 min after impact, valves S1, S2 and S3 are actuated, permitting compressed air to purge the sample manifold and allowing the pump to pull filtered ambient air to prevent pump burnout. The effect of the purging action on the particles collected in the cyclone is unknown. It is assumed some of the collected particles, if not all, are ejected into the ventilation stream.

The sampling of ventilation air at this location with this system is not to be considered ideally representative. Isokinetic sampling ${ }^{(a)}$ was not attempted since the cyclone design would not permit it and would be impossible to achieve in light of the expected rapid fluctuation in approach air velocity. The sample intake point was chosen in a region of average velocity under normal flow conditions. This choice does not necessarily ensure, however, that the

(a) Matching the air velocity through the sampler nozzle to the approaching air velocity--one condition for ideal representative sampling. 
particle concentration at the intake absolutely represents the average across the duct opening. However, this question is not considered important since the function of this monitor is more qualitative than quantitative.

\subsubsection{Operation}

To begin operation of the inlet monitor, verify that solenoid valves $S 1$ and $S 3$ are closed, that valve $S 2$ is open and that the RAM-1 inlet valve is in the CLEAR position (closed). The air compressor, RAM-1, amplifier and recorder can then be turned on to warm up. Valve $V 2$ is opened, and the pump and probe heater (if necessary in damp weather) are turned on. The sample airflow is then adjusted to $155 \mathrm{SCFH}$ by noting the vacuum and temperature gauge readings and using Table 1 to obtain the proper flowmeter set point. Flow is adjusted by valve V2. Flow adjustment is an iterative procedure and should be checked several times during the day. The power to the probe heater should be adjusted so that the sample air temperature is in the 60 to $80^{\circ} \mathrm{F}$ range. Because sample air temperature response is slow and is affected by the temperature of the sampling shelter as well as the probe heater, probe heat adjustment may be required occasionally throughout a day. It is recommended to set the sampler shelter thermostat to a temperature equal to or a few degrees lower than desired in the sampler line.

While the sampling system warms up, adjustments to the electronic components should be made. Begin by checking the zero reading of the RAM-1.

RAM-1 Zeroing. Begin the zeroing procedure by placing the RAM-1 inlet valve in the CLEAR (closed or horizontal) position and operating the instrument for a few minutes to flush the sensing chamber. Place the time constant switch on the 2-second position.

Starting on the 0 to $200 \mathrm{mg} / \mathrm{m}^{3}$ range check that the digital display reads zero on all ranges. Allow several seconds for the display to reach zero on each range. The zero reading on the 0 to $2 \mathrm{mg} / \mathrm{m}^{3}$ range is the most sensitive. A zero reading on this scale would be any reading that averaged zero over the range -0.005 to $+0.005 \mathrm{mg} / \mathrm{m}^{3}$. If this isn't the case, adjust the zero potentiometer. The instrument's sensing chamber and optics may need cleaning if, while on the 0 to $2 \mathrm{mg} / \mathrm{m}^{3}$ range, an averaged zero cannot be 
TABLE 1. Inlet Monitor Flowmeter Set Points(a) for Achieving 155 SCFH

Temp.

Gauge

Reading

Vacuum Gauge Readings, Inches Water

$\frac{\text { Deg. F. }}{0 .} \frac{0 .}{144 .} \frac{5 .}{145 .} \frac{10 .}{146 .} \frac{15 .}{147 .} \frac{20 .}{148 .} \frac{25 .}{149 .} \frac{30 .}{150 .} \frac{35 .}{151 .} \frac{40 .}{152 .} \frac{45 .}{153 .} \frac{50 .}{154 .} \frac{55 .}{155 .} \frac{60 .}{156 .}$

10. 146. 147. 148. 149. 150. 151. 152. 153. 154. 155. 156. 157. 158.

20. 148. 148. 149. 150. 151. 152. 153. 154. 155. 156. 158. 159. 160.

30. 149. 150. 151. 152. 153. 154. 155. 156. 157. 158. 159. 160. 161.

40. 151. 151. 152 153. 154. 155. 156. 157. 159. 160. 161. 162. 163.

50. 152. 153. 154. 155. 156. 157. 158. 159. 160. 161. 162. 164. 165.

60. 154. 154. 155. 156. 157. 158. 160. 161. 162. 163. 164. 165. 166.

70. 155. 156. 157. 158. 159. 160. 161. 162. 163. 164. 166. 167. 168.

80. 156. 157. 158. 159. 160. 161. 163. 164. 165. 166. 167. 168. 169

90. 158. 159. 160. 161. 162. 163. 164. 165. 166. 167. 169. 170.171.

100. 159. 160. 161. 162. 163. 164. 166. 167. 168. 169. 170. 171. 173.

110. 161. 162. 163. 164. 165. 166. 167. 168. 169. 170. 172. 173. 174.

120. 162. 163. 164. 165. 166. 167. 168. 170. 171. 172. 173. 174. 176.

130. 164. 165. 166. 167. 168. 169. 170. 171. 172. 173. 175. 176. 177.

140. 165. 166. 167. 168. 169. 170. 171. 173. 174. 175. 176. 177.179.

150. 166. 167. 168. 169. 171. 172. 173. 174. 175. 176. 178. 179. 180.

(a) The standard conditions for the flowmeters are air at $70^{\circ} \mathrm{F}, 1 \mathrm{~atm}$.

achieved within the tolerances specified above. A buildup of dust deposited in the sensing chamber and on the optics may scatter enough light to interfere with the zeroing procedure. Next, the recorder should be zeroed.

Recorder Zeroing. After power to the recorder has been on for a half an hour, place the recorder on the $50 \mathrm{mV} / \mathrm{cm}$ range, the ZERO/MEAS switch in the ZERO position and check that the pen reads zero. If not, adjust using the ZERO knob. Place the ZERO/MEAS switch in the MEAS position. Proceed to adjust the recorder gain to compensate for any bias in the RAM-1 output signal.

Recorder Gain Adjust. While the RAM-1 is in the calibrate mode ( 0 to $20 \mathrm{mg} / \mathrm{m}^{3}$ range, 2-second time constant, reference scatterer in, observe the letter "k" flashing on the upper right side of the LCD display), the recorder 
gain should be adjusted to bring the recorder into the best agreement with the RAM-1 readout because the RAM-1 output may be slightly biased. This adjustment is begun by zeroing the recorder and setting its scale on $50 \mathrm{mV} / \mathrm{cm}$. The CAL knob on the RAM-1 is turned until the readout indicates $0.5 \mathrm{mg} / \mathrm{m}^{3}$. (This generates an output voltage equivalent to the alarm level, $0.05 \mathrm{mg} / \mathrm{m}^{3}$, had the RAM- 1 been on the 0 to $2 \mathrm{mg} / \mathrm{m}^{3}$ range.) The variable gain knob on the recorder is then adjusted until the recorder reads a deflection of $0.25 \mathrm{~V}(5 \mathrm{~cm})$ to left of zero. This adjustment ensures that on the average the recorder chart can be accurately read to within $0.5 \%$ of the full-scale RAM-1 reading on any of the RAM-1 ranges. The accuracy of the recorder chart is best near the alarm point. Initially the gain adjustment should be performed daily, but experience may show a less frequent adjustment is necessary. Following this complete the secondary calibration of the RAM-1.

RAM-1 Secondary Calibration. While still in the calibrate mode, wait for $30 \mathrm{sec}$ for the reading to stabilize. The reading on the display should be adjusted using the CAL knob until it agrees with the value stamped on the plate next to the reference-scattering knob. Pull out the reference scattering knob. Now place the system into the measurement mode.

Measurement Procedure. Proper range, time constant, flow rate and alarm set point settings for the RAM-1 and recorder should be verified. For an action level of $0.05 \mathrm{mg} / \mathrm{m}^{3}$ concentration, the set points are:

- RAM-1 scale 0 to $2 \mathrm{mg} / \mathrm{m}^{3}$

- RAM-1 time constant $32 \sec ^{(a)}$

(a) The time constant can be switched to $0.5,2,8$, or $32 \mathrm{sec}$. As the time constant increases, the internal noise decreases and a more stable reading results at the expense of the ability to follow rapid fluctuations in aerosol concentration. Each four-fold increase in the time constant decreases internal noise by a factor of two and decreases the speed of instrument response. When average concentrations are of interest, a long time constant should be used. When concentration fluctuation is important, a shorter time constant should be used. If the RAM-1 ranges are changed during the monitoring period, using a short time constant decreases the data lost while the instrument responds to the range change as compared to the data lost if a long time constant was selected. 
- Recorder range

- Al arm set point

- Recorder chart speed
$50 \mathrm{mV} / \mathrm{cm}$

$0.25 \mathrm{~V}$ or $5 \mathrm{~cm}$

$20 \mathrm{~cm} / \mathrm{h}$. (a)

Place the inlet valve in the sample position and adjust the total flow to at least $2.2 \mathrm{lpm}$. Adjust the internal purge flow valve so that the total minus purge flow equals $2 \mathrm{lpm}$. The minimum purge flow is about $0.22 \mathrm{lpm}$. Before shutting off the RAM-1, put the inlet valve in the clear position and run for 3 min to allow purging of the optical cavity.

Set the alarm contact points on the recorder by grasping the alarm contacts located directly behind and above the chart paper and squeezing the sliding pieces together. The contacts may then be moved to the desired location in the same way that typewriter margins are set. For both recorders, the right-hand or low-contact limit point is the set point used. For both monitors, set the alarm level to $50 \mu \mathrm{g} / \mathrm{m}^{3}$ which corresponds to $0.25 \mathrm{~V}$ or a reading of $5 \mathrm{~cm}$ on the pen scale (when using the 0 to $2 \mathrm{mg}$ scale on the RAM-1 and the $50 \mathrm{mV} / \mathrm{cm}$ recorder scale). The low-limit contacts were used for the alarm rather than the high limit because the low-limit set point could be changed over a wider range than the high limit. To begin measurement, set recorder to MEAS and press START. Be sure to remove pen cap or no ink line will appear.

The recorded RAM-1 output is interpreted using the chart in Table 2 when the RAM-1 and recorder ranges are set as above. The signal transmission from the RAM-1 to the recorder and the digital voltmeter (at the gun) should be verified. With the RAM-1 on the 0 to $2 \mathrm{mg} / \mathrm{m}^{3}$ range, the digital voltmeter readout interpretation is as shown in Table 2 (concentration $\mathrm{mg} / \mathrm{m}^{3}=0.2 \times \mathrm{DC}$ volts).

After verifying the operation of the electronic components, the sample flow system is fine-tuned. The main air sampler flow is adjusted by valve

(a) When setting the recorder chart speed, set both the number of units (2, 6 , $20,60)$ and the units $(\mathrm{cm} / \mathrm{min}, \mathrm{cm} / \mathrm{h})$. With the instruments set as above, each centimeter deflection equals $0.01 \mathrm{mg} / \mathrm{m}^{3}$. 
TABLE 2. Inlet Monitor Recorder and Digital Voltmeter Interpretation

\begin{tabular}{|c|c|c|c|}
\hline $\begin{array}{l}\text { RAM-1 Signal } \\
\text { Voltage } \\
\end{array}$ & $\begin{array}{c}\text { Recorder Pen } \\
\text { Deflection, } \mathrm{cm}\end{array}$ & $\begin{array}{l}\text { Digital Voltmeter } \\
\text { Reading, Volts } \\
\end{array}$ & $\begin{array}{c}\begin{array}{c}\text { Concentration } \\
\mathrm{mg} / \mathrm{m}^{3}\end{array} \\
\end{array}$ \\
\hline 0.25 & 5 & 0.25 & 0.05 \\
\hline 1 & 20 & 1.0 & 0.2 \\
\hline 2 & Off Scale & 2.0 & 0.4 \\
\hline 4 & Off Scale & 4.0 & 0.8 \\
\hline 6 & Off Scale & 6.0 & 1.2 \\
\hline 8 & Off Scale & 8.0 & 1.6 \\
\hline 10 & Off Scale & 10.0 & 2.0 \\
\hline
\end{tabular}

V2. The manual valves $V 1$ and $V 3$ in the purge air system should be opened. The air compressor pressure should be about 90 psi and the regulator pressure should be set at about 50 psi. Briefly actuate the solenoid valves to verify purge air operation.

Immediately before a test firing, the $D C$ battery-powered voltmeter at the gun should be set on a $D C$ voltage range to furnish a remote readout of the RAM-1 output voltage. Also, just prior to shooting the round, the purge air system should be actuated by the switch located at the gun. The purge air should remain on until at least 1 min after the shot. It is expected that both the RAM-1 readout and output signals to the DC voltmeter and recorder will be well off scale for several minutes after the shot. (GCA has indicated that the RAM-1 output is linear with the concentration up to $15 \%$ beyond range.) When the alarm shuts off, it may be safe for personnel to enter the enclosure. This should be verified using the backup sampler. The monitor output should be recorded as long as needed to determine when the concentration decays to below 25\% MPC and as long as personnel are in the enclosure. If the alarm sounds while personnel are in the enclosure, ensure that the monitor signal is recorded by changing recorder and RAM scales as necessary and noting the changes on the chart. After the test firing, the $D C$ voltmeter may be turned off to conserve the battery. At the end of the day, the RAM-1 inlet valve should be placed in the clear position for a few minutes to purge the particles from the optical chamber. The RAM-1, recorder, amplifier, probe heater, compressor and pump can then be turned off. 
The minimum key operating data that should be recorded for each test firing are:

- Round number

- Date

- Time of shot

- Time recorder trace turned ON/OFF

- RAM-1 range

- RAM-1 time constant

- Recorder chart speed

- Recorder range.

These should be recorded on the recorder chart paper and in a log book. It may also be useful to save the recorder charts particularly if an alarm occurs when personnel are in the target enclosure. In these cases, it will also be useful to calculate the duration of the alarm, average concentration during the alarm and average concentration over the duration of the personnel exposure. A check list for inlet monitor operation is contained in Appendix B.

\subsection{EXHAUST MONITOR}

\subsubsection{Description}

This part of the air-sampling system monitors the air in the ventilation duct after it has passed through the HEPA filters. The primary function of the exhaust monitor is to provide documentation on the amount of aerosol released to the atmosphere. The exhaust monitor will also cause an alarm to go off if a sudden increase in aerosol concentration occurs, such as would occur if the exhaust filters were ruptured. A diagram of the exhaust monitor vacuum system is shown in Figure 5; a block diagram of the major electronics is shown in Figure 6. A schematic of the remote switching system is included in Appen$\operatorname{dix} A$ (Figure A.3).

The monitoring system consists of two subsystems: the sample manifold and the monitoring instrumentation. The sample manifold isokinetically withdraws air from the fan discharge duct at a rate of $99 \mathrm{SCFH}(47 \mathrm{lpm})$. A subsample stream is then isokinetically extracted from the manifold through a nozzle at a rate of $2 \mathrm{lpm}$. The balance of the sample air is filtered to trap 


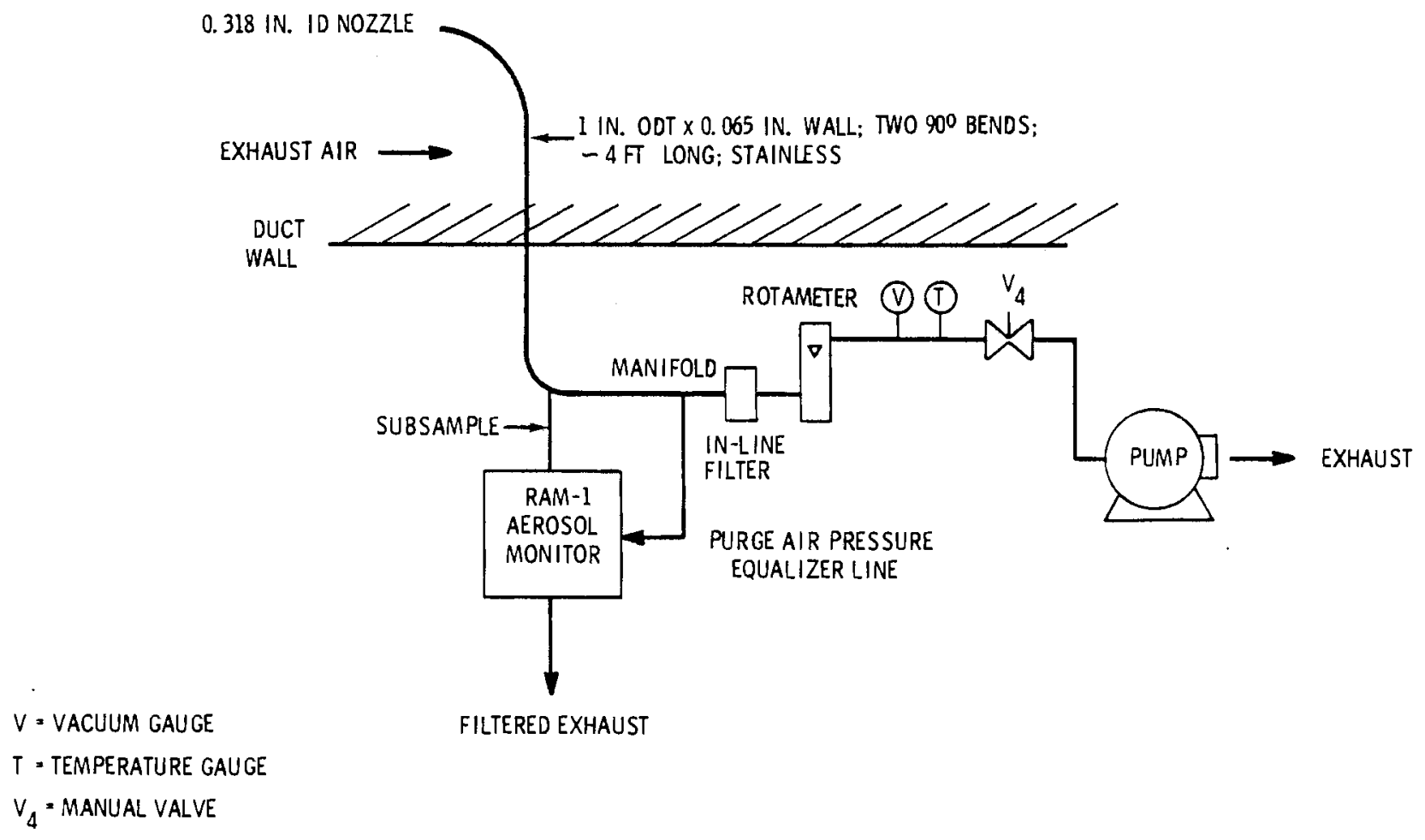

FIGURE 5. Exhaust Monitor Vacuum System

particles and is passed through the flowmeter, regulating valve and is expelled through the vacuum pump. As with the inlet monitor, the vacuum and temperature gauges aid the interpretation of the flowmeter readings. The flowmeter measures the total sample airflow minus the subsample flow and therefore is set on a reading equivalent to $47-2=45 \mathrm{lpm}$ ( 95 SCFH). Part of the sample manifold is heat traced in the same way as the inlet monitor.

The subsample stream is delivered to the inlet of a GCA RAM-1 that monitors the particle concentration in terms of $\mathrm{mg} / \mathrm{m}^{3}$. The inlet of the RAM-1 internal purge is also attached directly to the sampling manifold to improve purge flow by equalizing sample inlet and purge air pressures. After monitoring, the subsample air is filtered to remove particles and is then expelled to the atmosphere by the RAM-1. The RAM-1 output signal can be switched to a recorder that has high-level contacts to trigger audible and visual alarms at a given set point. This switching is accomplished by means of switches located both in the sampler shelter and near the gun station (see Figure 6). 


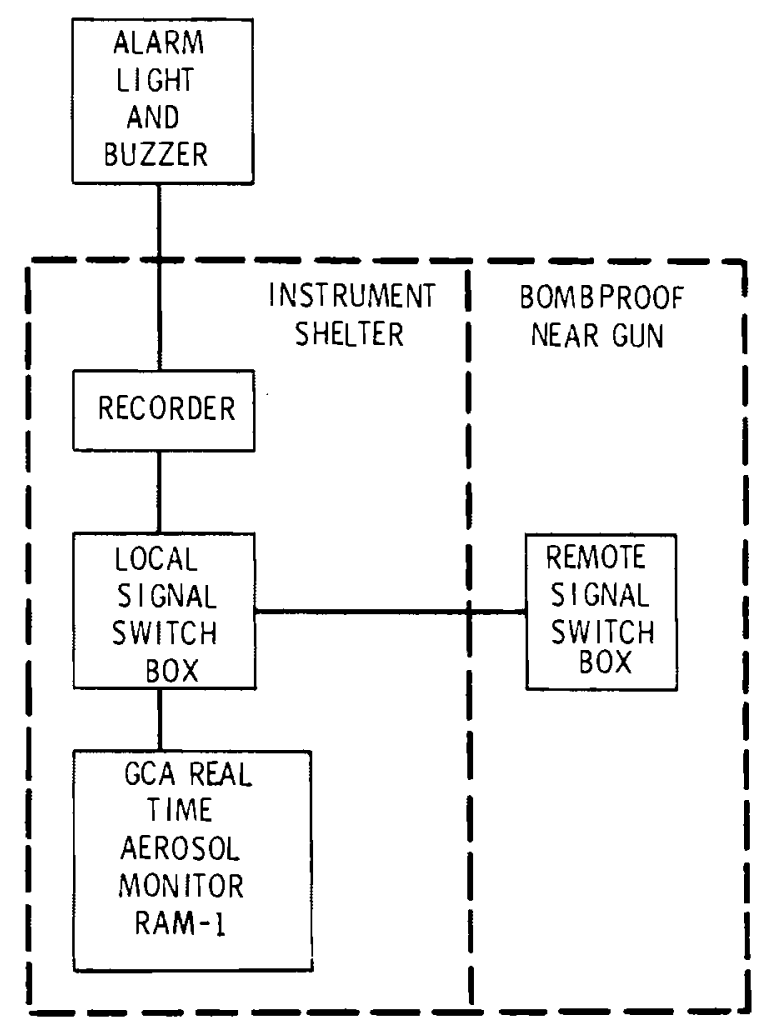

FIGURE 6. Exhaust Monitor Electronic Component Block Diagram

The configuration of this sampling system allows the ventilation system to be operated intermittently during a day (e.g., just before a test firing and for 30 min thereafter) without having to wait for the sampling system to warm up each time the ventilation is turned on. The pump, recorder and the RAM-1 can be turned on and flows set at the start of each day, and yet the record of particle concentration in the filtered exhaust is kept only when the ventilation system is operated. This is accommodated with the switch in the RAM-1 signal output. The signal should be recorded at all times the ventilation system is operated. Provision is made on the switching box to select an unswitched continuous signal if so desired. It is of no interest to record air concentration when the ventilation system is not operating. In fact, the indicated concentration would probably increase when the ventilation is off because the RAM-1 would then be sampling ambient air rather than filtered air. 


\subsubsection{Operation}

The operation of the exhaust monitor is similar to that of the inlet monitor described earlier except that the outlet monitor has no manifold purge system. To operate the exhaust monitor, turn on the pump, RAM-1 and recorder, open valve $\mathrm{V} 4$, and allow air to run through the system. It may be necessary to turn on the probe heater in cold weather to stabilize the sample air temperature at 60 to $80^{\circ} \mathrm{F}$. (Shelter temperature should equal or be a few degrees lower than desired sample air temperature.) Observe the temperature and pressure on the gauges. Find the flowmeter set point corresponding to that temperature and pressure on Table 3 and adjust the valve until the correct flow rate is indicated on the flowmeter. Adjust the RAM-1 zero as detailed in Section 3.1.2. Adjust the recorder gain and calibrate the RAM-1

TABLE 3. Exhaust Monitor Flowmeter Set Points for Achieving 95 SCFH

\begin{tabular}{|c|c|c|c|c|c|c|c|c|c|c|c|c|c|}
\hline Gaus & & & & & & & & & & & & & \\
\hline & 0. & 5. & 0. & 15. & & & & 35. & 40. & 45. & 50. & 55. & \\
\hline 0. & 89. & 89. & 90. & 90 . & 91. & 91. & 92. & 93. & 93. & 94. & 95. & 95. & \\
\hline 10. & 89. & 90. & 91. & 91. & 92. & 92. & 93. & 94. & 94. & 95. & 96. & 96. & \\
\hline 20. & 90. & 91. & 92. & 92. & 93. & 93. & 94. & 95. & 95. & 96. & 97. & 97. & \\
\hline 30. & 91. & 92. & 92. & 93. & 94. & 94. & 95. & 96. & 96. & 97. & 98. & 98. & \\
\hline 40. & 92. & 93. & 93. & 94. & 95. & 95. & 96. & 97. & 97. & 98. & 99. & 99. & 00 \\
\hline 50. & 93. & 94. & 94. & 95. & 96. & 96. & 97. & 97. & 98. & 99. & 100. & 100. & 10 \\
\hline 60. & 94. & 95. & 95. & 96. & 97. & 97. & 98. & 98. & 99. & 100 & 100. & 101. & 02 \\
\hline 70. & 95. & 96. & 96. & 97. & 97. & 98. & 99. & 99. & 100. & 101. & 101. & 102. & 103 \\
\hline 80. & 96. & 96. & 97. & 98. & 98. & 99. & 100 & 100. & 101. & 102. & 102. & 103. & \\
\hline 90. & 97. & 97. & 98. & 99. & 99. & 100. & 101. & 101. & 102. & 103. & 103. & 104. & 10 \\
\hline 100. & 98. & 98. & 99. & 100. & 100. & 101. & 101. & 102. & 103. & 104. & 104. & 105. & \\
\hline 110. & 99. & 99. & 100. & 100. & 101. & 102. & 102. & 103. & 104. & 104. & 105. & 106. & \\
\hline 120. & 99. & 100. & 101. & 101. & 102. & 103. & 103. & 104. & 105. & 105. & 106. & 107. & \\
\hline 130. & 100. & 101. & 101. & 102. & 103. & 103. & 104. & 105. & 106. & 106. & 107. & 108. & 10 \\
\hline 0. & 101. & 102. & 102. & 103. & 104. & 104. & 105. & 106. & 106. & 107. & 108. & 109. & \\
\hline 150. & 102. & 103. & 103. & 104. & 105. & 105. & 106. & 107. & 107. & 108. & 109. & 110. & \\
\hline
\end{tabular}


as detailed for the Inlet Monitor. Recorder, alarm and RAM-1 settings are the same as the Inlet Monitor (see page 19).

Next, check that there is enough chart paper in the recorder for anticipated usage. Turn the switch on the relay box until the light goes out. This indicates that the signal from the RAM-1 is not being transmitted to the recorder. Turn the switch back on whenever the ventilation system is operating. Also, check that the recorder pen cap is off and that the chart mechanism has been started. In the event that the ventilation system is shut down remotely, a switch for shutting off the recorder signal is located remotely at the gun station. The local and remote switches controlling the recorder signal also control the power for the outlet filter sampler pump. If the signal is to be turned off for an extended period of time, it would be wise to shut off the recorder chart to save paper. This can be done by pressing STOP. The signals to the inlet recorder and the exhaust recorder can both be switched off locally using the switch box or the ZERO switch on the recorder. When the recorder is not in use, the pen cap should be replaced on the pen. A checklist for the exhaust monitor operation is contained in Appendix $B$.

\subsection{EXHAUST FILTER SAMPLER}

\subsubsection{Description}

This part of the air-sampling system samples exhaust air after it has passed through the HEPA filters. The use of filter holders and filter paper, as opposed to an electronic aerosol detector, allows collecting a long-term, time-averaged exposure sample based on a gross alpha or uranium analysis. Long-term sampling is desirable to obtain sufficient material for accurate analysis. A diagram of the exhaust filter sampler vacuum system is shown in Figure 7; a block diagram of the major electrical components is shown in Figure 8.

This system is considerably simpler than the two monitor systems described earlier. The sample air is isokinetically withdrawn $(a)$ from the 26-3/4-in. $x$

(a) Based on an exhaust airflow of 18,000 SCFM. 


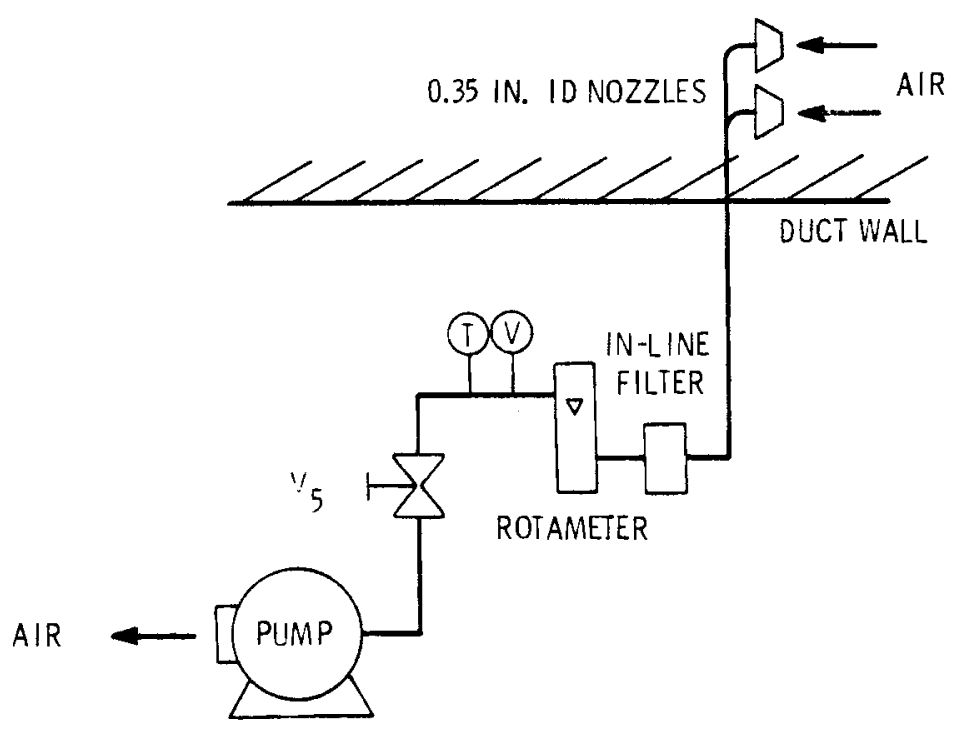

FIGURE 7. Exhaust Filter Sampler Vacuum System

34-1/2-in. fan exhaust duct through two parallel nozzles. The total flow rate is 240 SCFH or 120 SCFH per filter. A filter for collecting the particle sample is behind each nozzle. The sample air is then filtered to trap particles (if a sample filter fails) and then passes through the flowmeter, regulating valve and pump. The vacuum and temperature gauges assist in interpreting the flow reading. The probe is heat traced and temperature is controlled the same way as for the other systems. The vacuum pump can be turned on and off locally and near the gun station (see Figure 8 and Appendix A). It is intended that this sampler operate whenever the ventilation system does.

\subsubsection{Operation}

To operate the exhaust filter sampler, turn on the pump and open valve V5 to allow air to flow through the system. In cold or damp weather, turn on the probe heater until the temperature stabilizes at about 60 to $80^{\circ} \mathrm{F}$. Observe the temperature and pressure on the gauges and find the flowmeter set poirit corresponding to that temperature and pressure as shown in Table 4. Adjust Valve V5 until the correct flow rate is indicated. Allow the sampler to run as long as the ventilation system is in operation. The filter papers should be replaced weekly and the removed sample analyzed for uranium. The filters used 


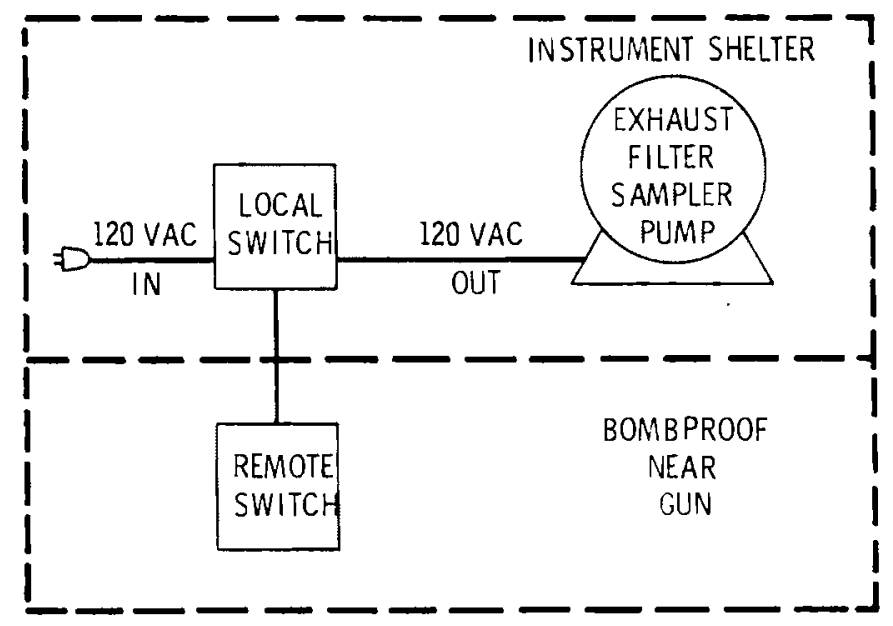

FIGURE 8. Exhaust Filter Sampler Instrumentation Block Diagram

are Gelman AN-3000 membrane filters ${ }^{(a)}$ with a $3-\mu m$ mean pore size and with a nylon mesh reinforcement.

The DOP (dioctylphthalate aerosol) efficiency for the AN-3000 filter is 97\% according to the manufacturer. Higher efficiency can be obtained using a smaller pore-sized filter (AN-1200 or AN-800 which decrease the flow through the sampler) or a glass fiber filter. The efficiency of the glass fiber filter is $99.9 \%$ for DOP according to the manufacturer. The selection of collection filter should be coordinated with the analytical lab; therefore, the correct counting and collection efficiencies are used in the analysis. For direct alpha-counting methods, membrane filters are generally preferred. When the filters are replaced, the inside of the filter holder nozzles should be swabbed out with a moist, lint-free cloth to reduce the chance for cross contamination.

A record of the following items should be kept for each set of filter samples collected:

- Sample description

- Operating time of sampler

- Sampler flow rate.

(a) Gelman Sciences, Inc., 600 S. Wagner Rd., Ann Arbor, Michigan 48106. 
TABLE 4. Exhaust Filter Sampler Flowmeter Set Points for Achieving 240 SCFH

Temp.

Gauge

Reading Vacuum Gauge Readings, Inches Mercury

$\frac{\text { Deg. } F .}{0 .} \frac{0 .}{224 .} \frac{2 .}{231 .} \frac{4 .}{240 .} \frac{6 .}{250 .} \frac{8 .}{261 .} \frac{10 .}{274 .} \frac{12 .}{289 .} \frac{14 .}{307 .} \frac{16 .}{328 .} \frac{18 .}{354 .} \frac{20 .}{388 .} \frac{22 .}{435 .} \frac{24 .}{503 .}$

10. 226. 234. 243. 253. 264. 277. 292. 310. 331. 358. 393. 439. 508.

20. 228. 236. 245. 255. 267. 280. 295. 313. 335. 362. 397. 444.513.

30. 231. 239. 248. 258. 270. 288. 298. 316. 338. 366. 401. 449. 519.

40. 233. 241. 250. 261. 272. 286. 301. 320. 342. 369. 405. 453.524.

50. 235. 244. 253. 263. 275. 289. 304. 323. 345. 373. 409. 458.529.

60. 238. 246. 255. 266. 278. 291. 307. 326. 349. 377. 413. 462. 534.

70. 240. 248. 258. 268. 280. 294. 310. 329. 352. 380. 417. 466.540.

80. 242. 251. 260. 271. 283. 297. 313. 332. 355. 384. 421. 471. 545.

90. 244. 253. 263. 273. 286. 300. 316. 335. 358. 387. 425. 475.550.

100. 247. 255. 265. 276. 288. 302. 319. 338. 362. 391. 428. 479.555.

110. 249. 258. 267. 278. 291. 305. 322. 341. 365. 394. 432. 484.560.

120. 251. 260. 270. 281. 293. 308. 324. 344. 368. 398. 436. 488. 564.

130. 253. 262. 272. 283. 296. 310. 327. 347. 371. 401. 440. 492. 569.

140. 255. 264. 274. 286. 298. 313. 330. 350. 374. 405. 443. 496. 574.

150. 257. 267. 277. 288. 301. 316. 333. 353. 377. 408. 447. 500.579.

The sampler flow rate should be checked frequently throughout its operation since the flow rate may change as the filters load up. Samples should be changed when the filters load up to the point where the system can no longer operate at the desired flow. In any case, the samples should be changed at least weekly, when the exhaust monitor alarms persistently, or as often as dictated by other requirements. A checklist for exhaust filter sampler operation is contained in Appendix B.

\subsection{WORKPLACE MONITOR}

The workplace monitor is designed to determine the aerosol concentration at the location where workers would be exposed. To operate the monitor, roll the cart that holds the RDM-301 into the enclosure and place it in the work area. Plug in the RDM-301 and turn the power switch on. Set the sampling 
time selector switches so that the desired sampling time is displayed. If the concentration of the air can be fairly accurately guessed, Figure 9 may be of use in setting the sampling time. For a "typical" working concentration of $20 \mathrm{\mu g} / \mathrm{m}^{3}$, a sampling time of 30 to $40 \mathrm{~min}$ would appear to be the minimum necessary sampling time. However, if the only function of the monitor is to trigger an al arm at 25\% MPC, the sampling time may be decreased to 15 to $20 \mathrm{~min}$. This would lead to inaccurate measurements of concentrations much lower than $25 \%$ MPC as shown in Figure 9.

After the sampling time has been set, set the mode switch to SINGLE or CONTINUOUS. If only one measurement is to be made, set the switch to SINGLE. If a series of measurements is to be taken, set the mode switch to

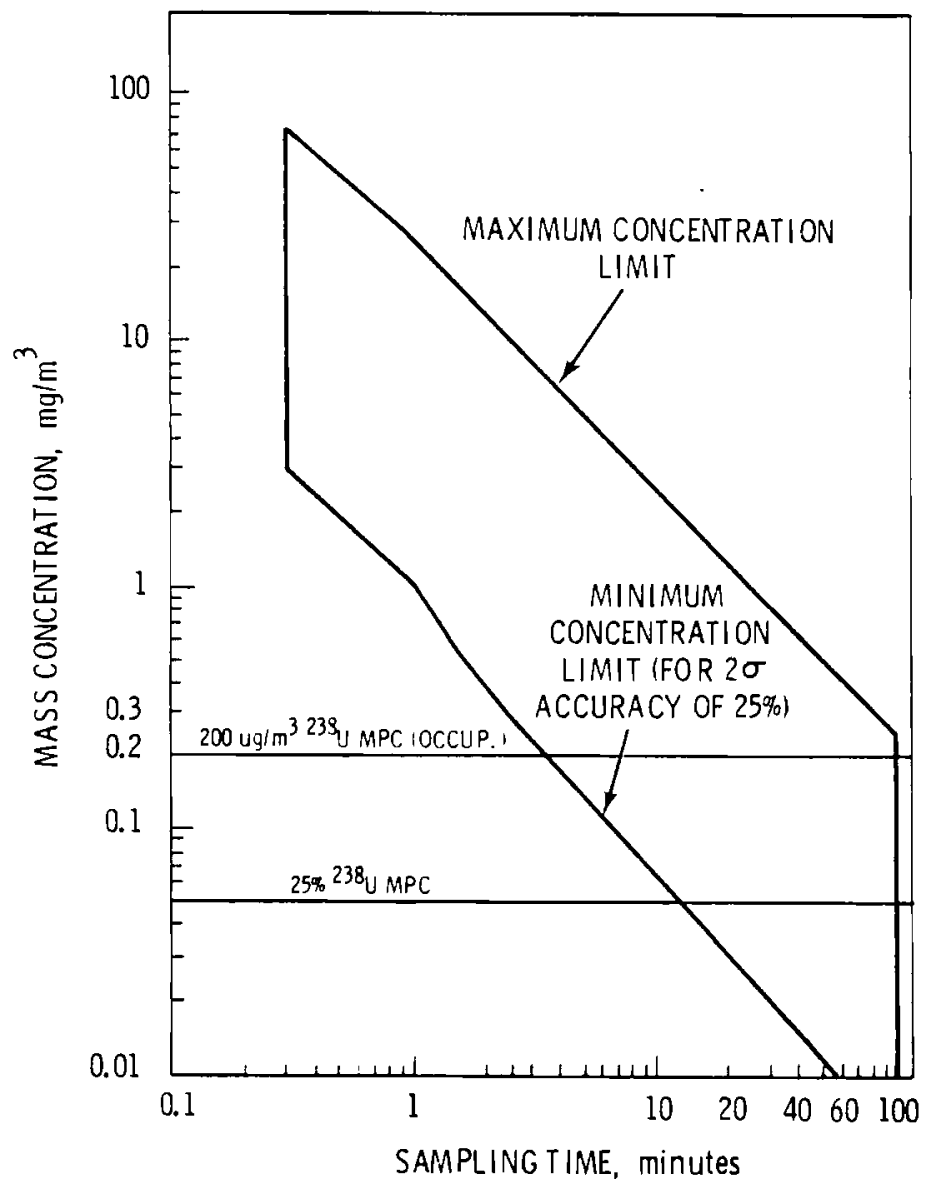

FIGURE 9. GCA Model RDM-301 Range Limits (operate instrument within closed area shown above) 
CONTINUOUS. This will allow the instrument to make a continuous series of measurements for up to 450 sampling periods.

After setting the mode switch, set the PRINT switch. If the PRINT switch is ON, the RDM-301 will print out the total sample time (in min), total milligrams collected, and last average concentration ( $\mathrm{in} \mathrm{mg} / \mathrm{m}^{3}$ ) at the end of each sampling interval. If the PRINT switch is OFF, the RDM-301 will accumulate the sampling time and total milligrams in memory, but will not print them. If these numbers are desired at any time, they may be obtained by setting the PRINT switch to ON, and waiting until the end of the next sampling interval, at which time the numbers will be printed. In any case, the PRINT switch must be $O N$ when in SINGLE mode or when the last of a series of measurements is being taken. Failure to do this will result in a loss of data.

After the PRINT switch is set, check that there is a mylar impaction disk under the inlet cover plate and that there is adequate printer tape for the desired sampling time. Do not be alarmed if the CHANGE DISC light comes on when the instrument is turned on. Now, press the START button (the CHANGE DISC light will go out) and attach the flowmeter to the inlet. Check that 2 lpm is flowing through the system (a reading of 2.1 on the flowmeter supplied is equal to $2.0 \mathrm{lpm})$. Also check the pressure drop on the front panel gauge. The gauge should read a vacuum of 8 to $10 \mathrm{in.} \mathrm{of} \mathrm{water.} \mathrm{Adjust} \mathrm{the}$ flow as necessary using the small set screw above the inlet cover plate. Remove the flowmeter and attach the cyclone. The RDM-301 is now sampling respirable particles.

To stop the RDM-301 if it is on the CONTINUOUS mode, set the mode switch to SINGLE and wait for it to stop at the end of the next sampling interval. Remember to turn the PRINT switch ON. If the CHANGE DISC light comes on in the middle of a series of samples, remove the old disc and replace it with a fresh disc. Reset the counter to zero at this time. When the counter nears 450 , the disc is close to needing replacement. Instructions for cleaning and preparing fresh discs are found in the RDM-301 manual. It is a good practice to clean the cyclone on a monthly basis. Other maintenance items regarding 
the alignment of the impactor nozzle (following the instrument being jarred severely) and the integrity of the carbon-14 source are covered on page 38 of the manufacturer's manual. Under no circumstance is any object to be inserted in the flow nozzle or detector holder openings.

\subsection{BACKUP SAMPLER}

The backup sampler is designed for manual operation. This instrument, the TSI 3500, was acquired for use in the event of failure of the other systems. The instrument can also be used as an additional workplace sampler. For example, it can verify workplace concentration before the gun crew is allowed into the enclosure for changing targets.

To operate the monitor, depress the PWR and CHK switches and look to see that the needle is within the blue portion of the meter scale. If not, then recharge the battery. Set the MEAS TIME button to $120 \mathrm{~S}$ for low concentrations. Then press the STRT button and check that the number on the digital display is between 2000 and $3000 \mathrm{~Hz}$. If it is much over $2300 \mathrm{H}_{z}$, the sensor should be cleaned (as outlined in the TSI 3500 manual). Then press the MEAS switch and look to see that the needle is within the black portion of the scale. If not, clean the precipitator needle assembly. To start measuring, press the STRT button again and wait $2 \mathrm{~min}$. At this time the TSI 3500 will display the concentration in $\mathrm{mg} / \mathrm{m}^{3}$. The concentration may also be estimated by the change in frequency displayed during the sampling interval. (For more complete discussion, see the TSI 3500 manual.) While using the TSI 3500 in the enclosure, a circuit may be walked during the 2-min sampling period to obtain an average of the whole enclosure, or the instrument may be left in one place to give a reading for that area. The sensor should be cleaned every five measurements (at low concentrations) and at the end of the day.

\subsection{INSTRUMENT MAINTENANCE}

Included here are most of the simple maintenance items that are performed frequently. The operator should be thoroughly familiar with the manufacturer's operating manual before attempting any of these maintenance steps. 


\subsubsection{RAM-1}

Described here are maintenance procedures for the RAM-1 including filter replacement, desiccant replacement, removal from sampling manifold, and leak checking. The operator is advised to be familiar with the manufacturer's manual on the RAM-1 since topics such as instrument malfunctions and cleaning the optics are not discussed here.

Filter and Desiccant Replacement. The two filter cartridges may be replaced by opening the flow chamber cover, removing the black flow manifold block, and removing the cartridges. When replacing the filter cartridges, be sure the flow direction arrow on the cartridge matches the arrow on the bottom of the flow chamber. Both arrows should point inward (see Figure 10).

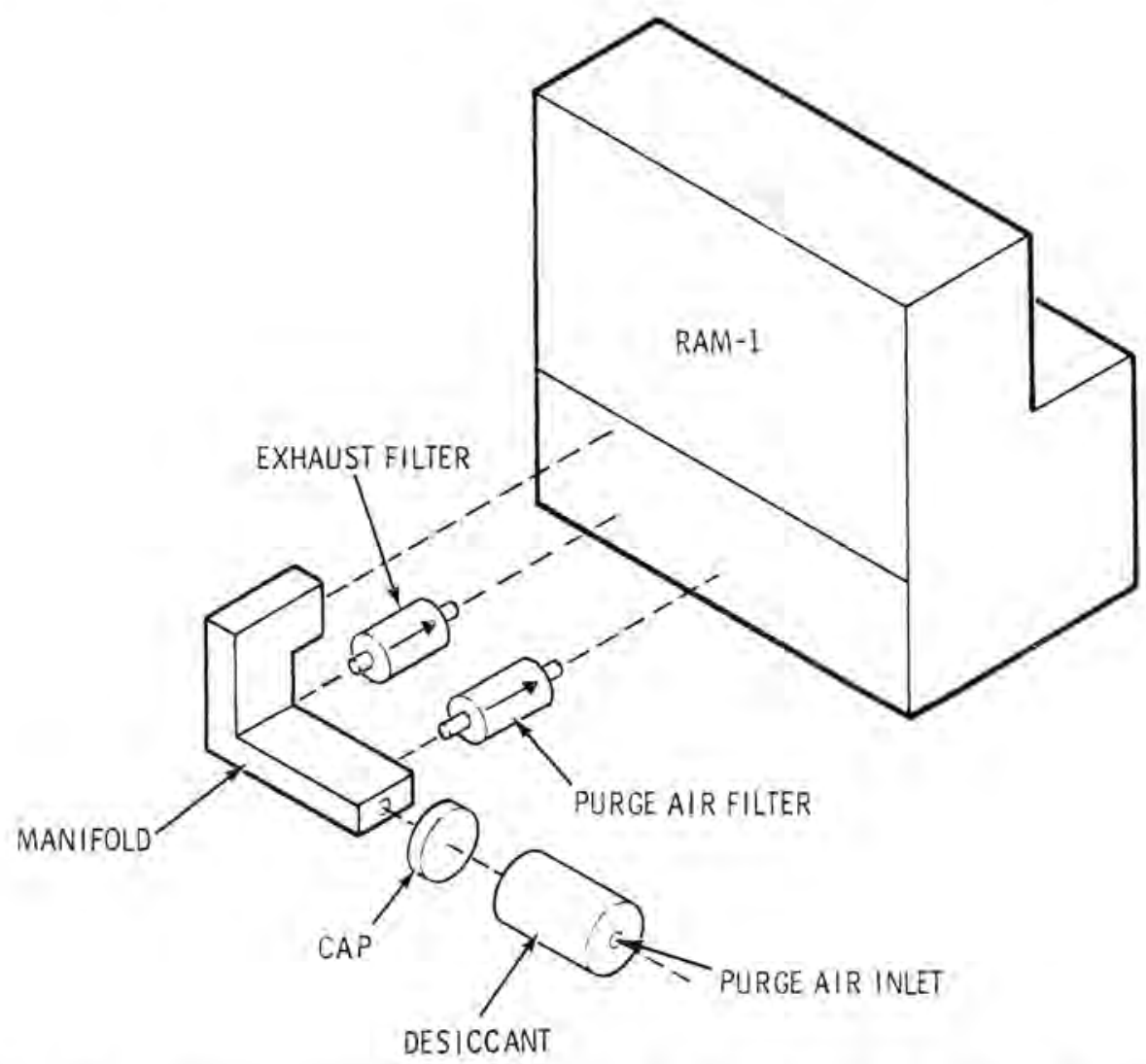

FIGURE 10. Instaliation of FiTter and Desiccant Cartridges in RAM-1 
The desiccant should be changed when its normal blue color turns pink. To do this, remove the cartridge, unscrew the lid of the cartridge, empty out the old "Dryerite" and refill the cartridge. Fill only the annular area around the central core.

Removal from Sampling Manifold. The RAM-1 can be removed from the sampling manifold for maintenance or use as a portable monitor. First, disconnect the tube-fitting nut from RAM-1 inlet. Then, loosen the tube-fitting nut from the sampling manifold elbow. Slide the RAM-1 probe up into the manifold; be careful not to lose the plastic ferrules. Then, slide the RAM-1 out from underneath the probe.

If the stainless-steel adapter fitting on the RAM-1 inlet is removed, do not lose the black plastic flow restricter because it must be reinserted before reassembly. The restricter helps maintain a pressure balance in the sensing volume of the instrument. Reconnecting the RAM-1 to the manifold is essentially the reverse of the above steps. The tube fittings should only be tightened one complete turn after finger tight.

Leak Checking. To check for air leaks internal to the RAM-1, close the inlet valve. Notice that the speed of the internal pump decreases audibly. Place a finger over the intake to the desiccant cartridge. If the pump speed does not drop off more, there is an in-leakage in the instrument. Leaks in sampling probes can be checked by closing all openings and pressurizing the probe. Soap solution spread on joints will bubble if leakage occurs.

\section{6 .2 TSI 3500}

Table 5 lists the maintenance checks that are done frequently. The instructions for performing these items are located in the TSI 3500 manual.

\subsubsection{Yokogawa Model 3056-11 Recorder (a)}

Instrument maintenance should consist of replacement of ink cartridges and paper, when necessary. The recorder should be lubricated every 3 mo as shown in the recorder manual and with the lubricant provided with the recorder.

(a) Yokogawa Corporation of America, 5, Westchester Plaza, Elmsford, New York 10523. 
TABLE 5. Suggested Maintenance Schedule for TSI 3500 Piezobalance

1. Daily

a. Check the sensor-cleaning sponges--add water, detergent, or clean as needed.

b. Recharge the batteries.

c. Check the impactor and clean if necessary.

2. Weekly

a. Clean both sensor-cleaning sponges thoroughly.

3. Every Two Weeks

a. Clean the precipitator needle assembly.

b. Check the sound of the vacuum pump for air leaks.

4. Every Six Months

a. Clean the vacuum pump.

b. Check the airflow rate.

5. Yearly

a. Return the Piezobalance to TSI Incorporated for complete cleaning, checkout and recalibration.

\subsubsection{Pumps}

Keep the oil jars on the pumps full of 10W detergent automotive oil. If the pump sounds noisy or is not performing we11, remove the pump from the system and add several teaspoons of nonflamable solvent to the intake while the unit is running. Lay the unit on its side so solvent will drain out. If this flushing does not work, the pump may be disassembled by removing the four end bolts. Refer to the pump owner's manual for details on disassembly.

\subsubsection{Flowmeters}

The only maintenance for flowmeters is an occasional cleaning. Remove the flowmeter from its bracket, remove the slip cap on top and screw out the plug ball using an appropriate Allen wrench. Remove the float and wash the tube and body in soap and water. Do not use any other solvents. For more details, see the flowmeter instruction sheet. 


\subsubsection{Fuses}

An adequate supply of fuses should be kept on hand so that replacement of the fuses in the monitor control systems does not cause delay.

\subsubsection{Contamination}

The following list describes those system components that may possibly become internally contaminated with uranium oxide particles during normal operation. These components should be handled as low-level contaminated articles:

- TSI 3500 impactor

- TSI 3500 sponges

- RDM-301 impaction discs

- RDM-301 cyclone

- RDM-301 filter

- RAM-1 exhaust filter

- RAM-1 dampener

- RAM-1 pump

- RAM-1 optics

- RAM-1 probes

- Outlet filter sampler probes

- Inlet monitor cyclone.

Tracking of contaminated material into the instrument shelters may also be possible. Attempts to clean foot gear prior to entering the shelters would be helpful. 
APPENDIX A

ELECTRICAL SCHEMATICS 


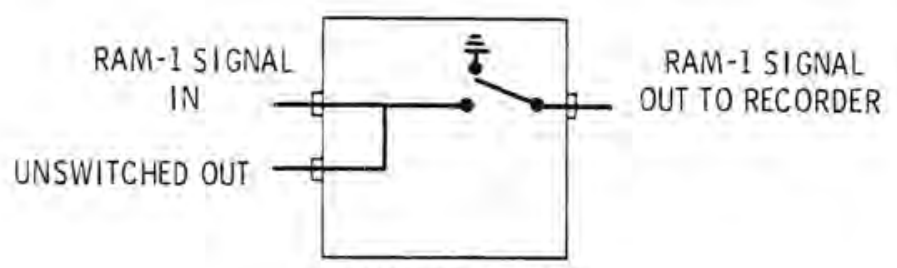

IN SAMPLER SHELTER

FIGURE A.1. Inlet Monitor RAM-1 Signal Switch Box

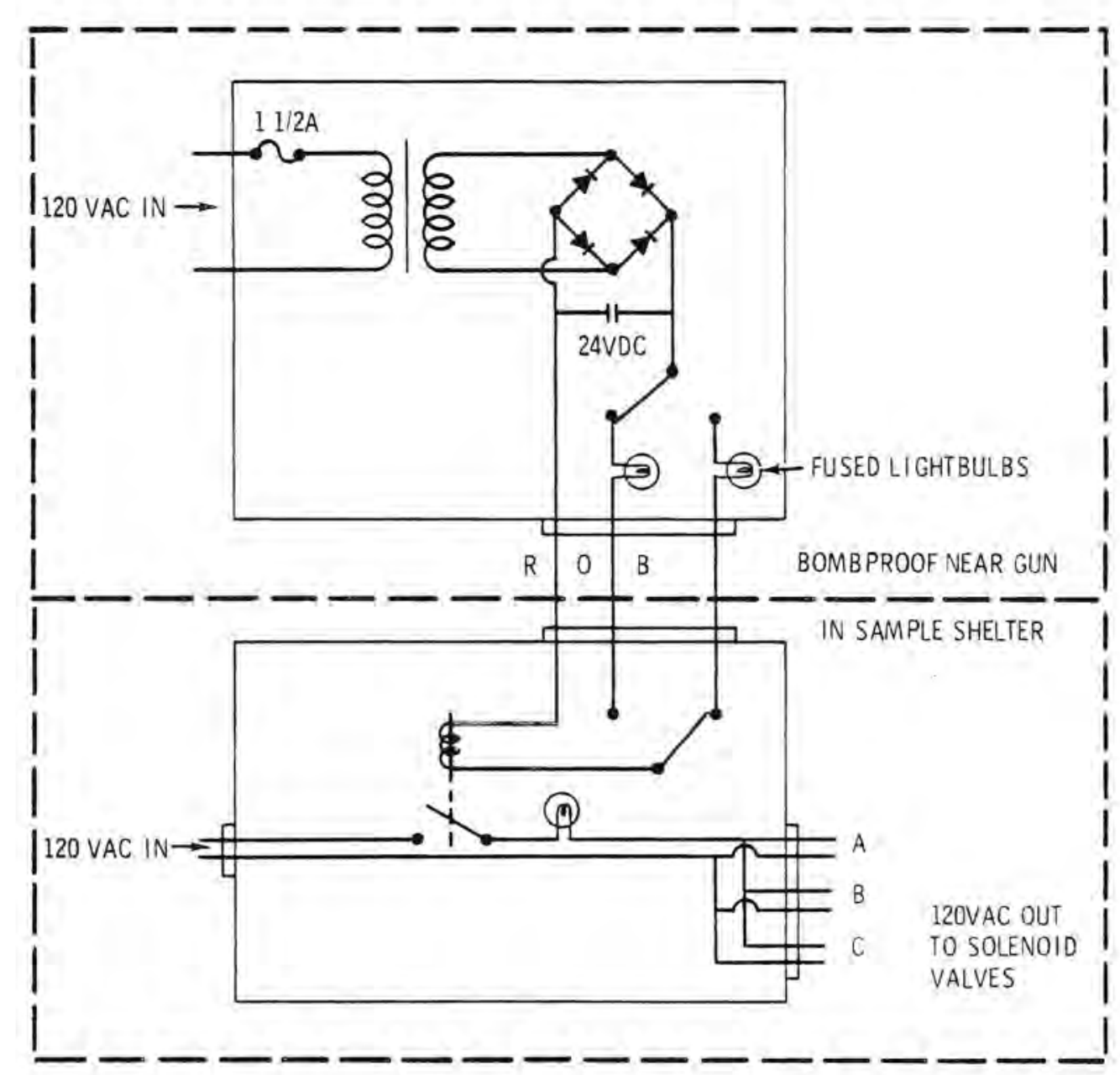

FIGURE A.2. Inlet Monitor Solenoid Valve Control Electrical Schematic 


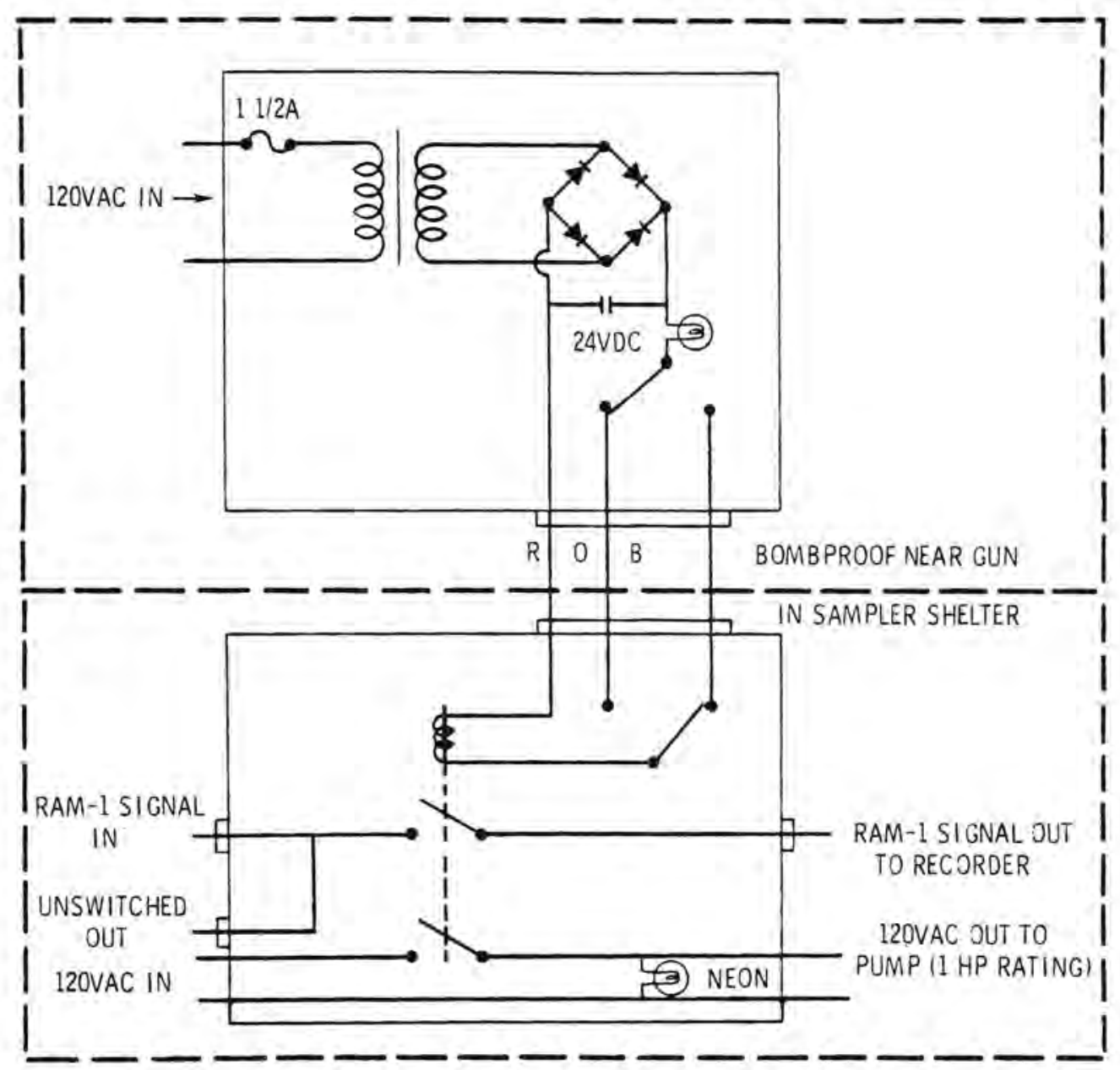

FIGURE A.3. Control Circuit for Exhaust Filter Sampler and Exhaust Monitor Signal 
APPENDIX B

OPERATING CHECKLISTS 
TABLE B.1. Check list for Operating Inlet Monitor

1. Verify solenoid valves in sampling position.

2. Turn instruments on.

3. Zero RAM-1 and recorder.

4. Adjust recorder gain.

5. Calibrate RAM-1.

6. Check signal continuity.

7. Adjust RAM-1 flow rates.

8. Set pressures on purge and verify purge operation.

9. At gun, plug in DVM on DC-volt range.

\section{Test Firing}

10. Turn purge on just before firing.

11. Turn purge off about $30 \mathrm{sec}$ after firing.

12. Record monitor output for as long as needed.

13. Turn off DVM.

Day's End

14. Purge RAM-1.

15. Turn off instruments.

16. Record key operating times. 
TABLE B.2. Checklist for Operating Exhaust Monitor

1. Turn instruments on.

2. Set valve for correct flow rate.

3. Zero RAM-1 and recorder.

4. Adjust recorder gain.

5. Calibrate RAM-1.

6. Adjust RAM-1 flow rates.

7. Check recorder paper and signal.

Test Firing

8. Start chart and signal.

9. Record monitor output while ventilation on.

Day's End

10. Purge RAM-1.

11. Turn off instruments.

12. Record key operating times.

TABLE B.3. Checklist for Operating Exhaust Filter Sampler

1. Turn instruments on.

2. Set valve for correct flow rate.

3. Turn pump off.

Test Firing

4. Start pump when ventilation started.

5. Leave sampler on while ventilation on.

Day's End

6. Stop pump.

7. Replace sample filters. 
PNL -3361

UC-11

\section{DISTRIBUTION}

No. of

Copies

\section{OFFSITE}

A. A. Churm

DOE Patent Division

9800 S. Cass Avenue

Argonne, IL 60439

25 Commander

Material Testing Directorate

STEAP-MT-A

Mr. Ken Ruff

Aberdeen Proving Grounds

MD 21005

27 DOE Technical Information Center

ONSITE

DOE Richland Operations Office

H. E. Ransom
No. of

Copies

20 Pacific Northwest Laboratory

C. E. Elderkin

R. Gilchrist

G. A. Gl issmeyer (5)

R. K. Hadlock

M. Halverson

G. B. Long

J. Mishima

S. L. Sutter

R. K. Woodruff

Technical Information (5)

Publishing Coordination (YO) (2) 


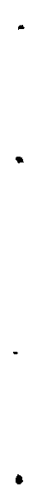

- 